Award Number: W81XWH-12-1-0605

TITLE: Molecular Indicators of Castration-5 esistant Prostate Cancer

PRINCIPAL INVESTIGATOR: Jun Luo, Ph.D.

CONTRACTING ORGANIZATION: Johns Hopkins University

Baltimore, MD 21218-2680

REPORT DATE: October 2014

TYPE OF REPORT: Annual

PREPARED FOR: U.S. Army Medical Research and Materiel Command Fort Detrick, Maryland 21702-5012

DISTRIBUTION STATEMENT: Approved for Public Release; Distribution Unlimited

The views, opinions and/or findings contained in this report are those of the author(s) and should not be construed as an official Department of the Army position, policy or decision unless so designated by other documentation. 


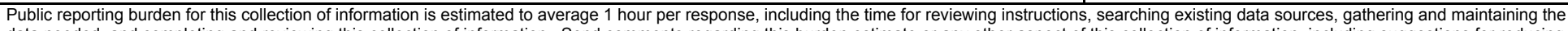

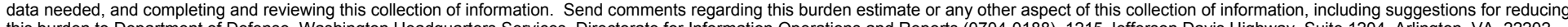

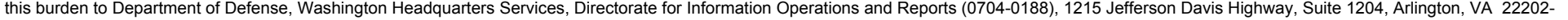

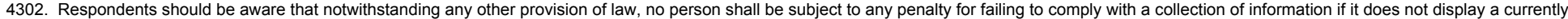
valid OMB control number. PLEASE DO NOT RETURN YOUR FORM TO THE ABOVE ADDRESS.

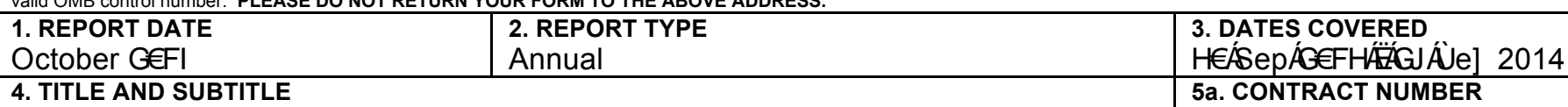

\section{Molecular Indicators of Castration-Resistant Prostate Cancer}

\section{5b. GRANT NUMBER}

W81XWH-12-1-0605

5c. PROGRAM ELEMENT NUMBER

\section{AUTHOR(S)}

Jun Luo, Ph.D.

5d. PROJECT NUMBER

5e. TASK NUMBER

5f. WORK UNIT NUMBER

E-Mail: jluo1@jhmi.edu

7. PERFORMING ORGANIZATION NAME(S) AND ADDRESS(ES)

Johns Hopkins University

8. PERFORMING ORGANIZATION REPORT NUMBER

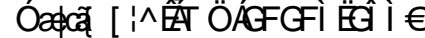

\section{U.S. Army Medical Research and Materiel Command}

9. SPONSORING / MONITORING AGENCY NAME(S) AND ADDRESS(ES)

Fort Detrick, Maryland 21702-5012

11. SPONSOR/MONITOR'S REPORT NUMBER(S)

\section{DISTRIBUTION / AVAILABILITY STATEMENT}

Approved for Public Release; Distribution Unlimited

\section{SUPPLEMENTARY NOTES}

\section{ABSTRACT}

Metastatic prostate cancers are commonly treated by agents designed to suppress androgen receptor (AR) signaling mediated by the full-length AR (AR-FL). Why some patients progress rapidly after treatment while others benefit with prolonged remission is an unsolved question. We propose approaches to develop molecular indicators of response and resistance that will enable prediction (before therapy) or early detection (during therapy) of therapeutic benefit. We will test the hypothesis that AR splice variants (AR-Vs) are molecular indicators of castration-resistant prostate cancer (CRPC). During this funding period, we achieved a major milestone by completing RNA sequencing of 48 CRPC specimens and publishing data on 4 specimens focusing on the analysis of transcriptional programs mediated by one of most important AR-Vs, AR-V7. We achieved another major milestone by establishing an association of AR-V7 with resistance to two major therapies targeting the androgen axis. We conclude that detection of AR-V7 predicts treatment outcome in men with metastatic castration-resistant prostate cancer initiating AR-targeting therapies.

\section{SUBJECT TERMS}

$127+, 1 *[/, 67('$

\begin{tabular}{|c|c|c|c|c|c|}
\hline \multicolumn{3}{|c|}{ 16. SECURITY CLASSIFICATION OF: } & \multirow{2}{*}{$\begin{array}{l}\text { 17. LIMITATION } \\
\text { OF ABSTRACT } \\
\text { UU }\end{array}$} & \multirow{2}{*}{$\begin{array}{l}\text { 18. NUMBER } \\
\text { OF PAGES } \\
\qquad 9\end{array}$} & \multirow{2}{*}{$\begin{array}{l}\text { 19a. NAME OF RESPONSIBLE PERSON } \\
\text { USAMRMC } \\
\text { 19b. TELEPHONE NUMBER (include area } \\
\text { code) }\end{array}$} \\
\hline $\begin{array}{r}\text { a. REPORT } \\
U\end{array}$ & $\begin{array}{c}\text { b. ABSTRACT } \\
U\end{array}$ & $\begin{array}{c}\text { c. THIS PAGE } \\
U\end{array}$ & & & \\
\hline
\end{tabular}




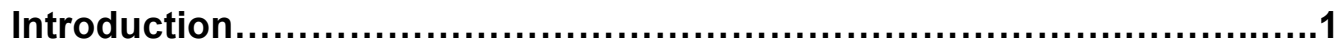

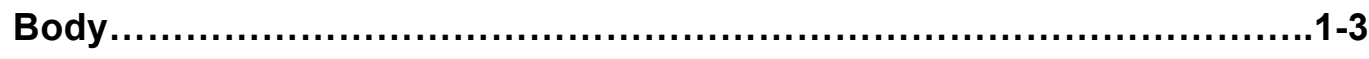

Key Research Accomplishments..................................... 3

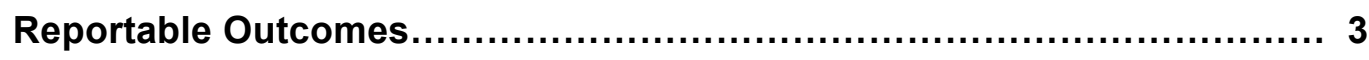

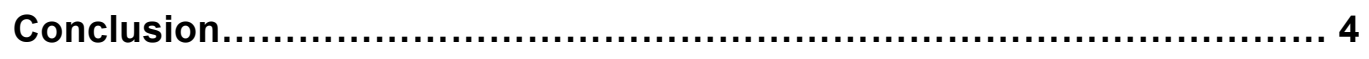

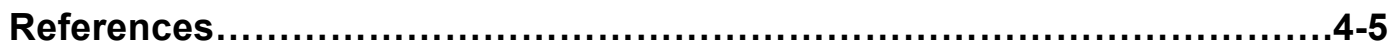

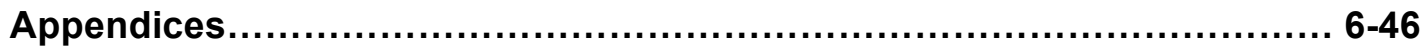

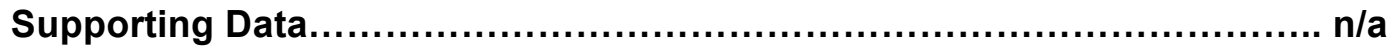




\section{Introduction}

Hormone therapies block androgen production and/or androgen receptor (AR) function leading to a period of clinical regression varying from months to more than 6 years among patients treated for metastatic prostate cancer. Because restored AR signaling is the key determinant of castration-resistant prostate cancer (CRPC), aberrant variants of the androgen receptor may mediate and indicate therapeutic resistance. Our recent efforts (1-3) have established that truncated androgen receptor splice variants (AR-Vs) are resistant to castration therapies that target the canonical full-length AR (AR-FL). We are now equipped with the knowledge that AR-Vs are both structurally and functionally distinguishable from the full-length AR (AR-FL), which remains the key target in prostate cancer drug design. We view these new discoveries and knowledge as opportunities that have yet to be capitalized to address the unmet need of developing indicators of castration resistance. In our previous studies, we have shown elevated expression of the AR-Vs following suppression of AR-FL (3). The primary purpose of the project is to discover and develop molecular indicators of CRPC by targeting the AR-Vs. We will test the hypothesis that AR-Vs are molecular indicators of CRPC. The scope of the proposed research is: 1) to perform RNA-Seq targeting transcripts originated from the human AR gene locus for $a b$ initio cataloging of AR-Vs that define CRPC; and 2) to establish the proof-of-principle that AR-Vs detected prior to the initiation of hormone therapies may be used to predict CRPC progression.

\section{Body}

Findings resulting from Task 1: To employ a novel targeted RNA-Seq method for $a b$ initio cataloging of androgen receptor variants that define CRPC (Months 1-24).

Summary: We have generated raw RNA sequencing data from 48 clinical specimens. This achievement represents a critical project milestones associated with Task 1 (subtask 1e) as outlined in SOW. As stated in SOW, data analysis is focusing on discovery of novel AR splice variants. Such effort is still ongoing. Of importance, RNA sequencing data from four metastatic castration-resistant prostate cancer specimens relevant to the specific analysis of the AR variant-driven signature was recently published (4), and included in Appendix of this progress report. On the basis of initial analysis from the 4 specimens with varying levels of AR-V7, we conclude that AR-V7 drives the expression of a unique set of genes, and confirmed that it is also the most abundantly expressed androgen receptor splice variant $(5,6)$.

Supporting data: Supporting data can be found in the Appendix of this progress report (4). Briefly, genome-wide comparisons of two AR-V7-negative and two AR-V7positive metastatic tumor samples by means of gene-set enrichment analysis of RNA sequencing data (Figs. S9 and S10 in the Supplementary Appendix of the attached paper), or by means of targeted analysis of a set of genes regulated by the canonical androgen receptor (Table S5 in the Supplementary Appendix of the attached paper) revealed 
alterations consistent with a shift toward AR-V7-driven transcription in AR-V7-positive samples.

Findings resulting from Task 2: To establish the proof-of-principle that AR-Vs detected prior to the initiation of hormone therapies may be used to predict CRPC progression (Months $1-36)$.

Summary: We have focused on the predictive value of AR-V7 in men with metastatic prostate cancer initiating therapies with the FDA-approved second-generation agents targeting the androgen and androgen receptor axis. These newer agents, abiraterone and enzalutmide, have transformed the treatment landscape for prostate cancer, and provided an ideal treatment context to test our hypothesis. In our recent study published in the New England Journal of Medicine (Appendix of this progress report) (4), we examined associations between baseline AR-V7 status and treatment outcomes including PSA response rates and clinical/radiographic-progression-free-survival (PFS). We analyzed 31 enzalutamide-treated patients and 31 abiraterone-treated patients, of which $38.7 \%$ and $19.4 \%$ had detectable AR-V7 in circulating tumor cells, respectively. Among men receiving enzalutamide, AR-V7-positive patients had substantially inferior PSA response rates $(0 \%$ vs $52.6 \%, \mathrm{P}=0.004)$ and shorter PFS (median: 2.1 vs 6.1 months, $\mathrm{P}<0.001$ ) compared to AR-V7-negative patients. Similarly, among men receiving abiraterone, ARV7-positive patients had inferior PSA response rates $(0 \%$ vs $68.0 \%, \mathrm{P}=0.004)$ and shorter PFS (median: 2.3 months vs not reached, $\mathrm{P}<0.001$ ). Importantly, no patient with detectable AR-V7 in the baseline CTC sample achieved a PSA response or radiographic response to enzalutamide or abiraterone. The negative prognostic impact of AR-V7 was maintained after adjusting for clinical factors including prior treatments as well as expression of ARFL. We conclude that detection of AR-V7 in CTCs from patients with CRPC is associated with primary resistance to enzalutamide and abiraterone, supporting the clinical utility of this blood-based predictive biomarker.

Supporting data: All supporting data can be found in our published paper (4), attached in the Appendix of this progress report. Briefly, 39\% of enzalutamide-treated patients (12 of 31 patients) and $19 \%$ of abiraterone-treated patients ( 6 of 31 patients) had detectable ARV7 mRNA in baseline CTC samples. Among the samples with detectable AR-V7, the median ratio of AR-V7 to full-length androgen receptor mRNA was $21.0 \%$ (range, 1.8 to 208.0) (Fig. 1 of the attached Appendix). In the enzalutamide cohort, the PSA response rate among AR-V7-positive patients was $0 \%$ (95\% CI, 0 to $26 ; 0$ of $12 \mathrm{men})$, and the rate among AR-V7-negative patients was 53\% (95\% CI, 29 to 76; 10 of 19 men; P = 0.004) (Figure 2A of the attached Appendix). In the abiraterone cohort, the PSA response rate among AR-V7-positive patients was $0 \%(95 \% \mathrm{CI}, 0$ to $46 ; 0$ of $6 \mathrm{men})$, and the rate among AR-V7-negative patients was $68 \%$ (95\% CI, 46 to $85 ; 17$ of 25 men; $\mathrm{P}=0.004)$ (Figure $2 \mathrm{~B}$ of the attached Appendix). Overall inferior treatment outcome in AR-V7 positive men was also demonstrated in Figure 3 of the attached Appendix, in which clinical progressionfree survival and overall survival rates were evaluated and compared between AR-V7 positive and AR-V7 negative patients. During the project period, 6 patients ( 4 receiving 
enzalutamide and 2 receiving abiraterone) who were negative for AR-V7 at baseline subsequently converted to AR-V7-positive status during the course of treatment, while all evaluable patients with detectable AR-V7 at baseline who had at least one follow-up sample available remained AR-V7-positive during treatment. Clinical outcomes for all patients according to AR-V7 conversion status are summarized in Table S4 in the attached Appendix. In addition, changes in levels of AR-V7 expression during the course of treatment are summarized in Figure S5 in the attached Appendix. Finally, we also showed high concordance of AR-V7 status in CTC and matched biopsy specimens from the same patient (Fig. 4 of the attached Appendix).

\section{Key Research Accomplishments}

1. Completed raw RNA-seq data collection from 48 samples.

2. Published data on 4 specimens relevant to the treatment with abiraterone and enzalutamide.

3. Published a high-impact study investigating the predictive value of AR-V7 in men with metastatic prostate cancer initiating treatments with abiraterone and enzalutamide.

\section{$\underline{\text { Reportable Outcomes }}$}

Publication:

Antonarakis ES, Lu C, Wang H, Luber B, Nakazawa M, Roeser JC, Chen Y, Mohammad TA, Chen Y, Fedor HL, Lotan TL, Zheng Q, De Marzo AM, Isaacs JT, Isaacs WB, Nadal R, Paller CJ, Denmeade SR, Carducci MA, Eisenberger MA, Luo J. AR-V7 and resistance to enzalutamide and abiraterone in prostate cancer. The New England journal of medicine. 2014;371(11):1028-38. Epub 2014/09/04. doi: 10.1056/NEJMoa1315815. PubMed PMID: 25184630. PMCID: In Process

Presentations:

1. Antonarakis E, Lu C, Wang H, Luber B, Nakazawa M. Androgen receptor splice variant, AR-V7, and resistance to enzalutamide and abiraterone in men with metastatic castration-resistant prostate cancer (mCRPC). J Clin Oncol. 2014;32(5 Suppl).

2. Antonarakis ES, Lu C, Wang H, Luber B, Nakazawa M, Roeser JC, Chen Y, Fedor HL, Lotan TL, De Marzo AM. Androgen receptor splice variant-7 predicts resistance to enzalutamide in patients with castration-resistant prostate cancer. Cancer research. 2014;74(19 Supplement):2910-.

Grant Applications:

Title: The aberrant androgen receptor underlies abiraterone/enzalutamide resistance 
Supporting Agency: NIH (Luo - PI)

Name of Procuring Contracting/Grants Officer: TBD - NIH

Address of Funding Agency: 9000 Rockville Pike, Bethesda, MD 20892

Performance Period: 4/1/2015 - 3/31/2020

Level of Funding: $\$ 250,000$

Status: A1 Submitted on July $5^{\text {th }}, 2014$

\section{Conclusion}

We conclude that AR-V7 drives the expression of a unique set of genes, and is the most abundantly expressed androgen receptor splice variant We further conclude that detection of AR-V7 in CTCs from patients with CRPC is associated with primary resistance to enzalutamide and abiraterone, supporting the clinical utility of this blood-based predictive biomarker.

\section{References}

1. Hu R, Dunn TA, Wei S, Isharwal S, Veltri RW, Humphreys E, Han M, Partin AW, Vessella RL, Isaacs WB, Bova GS, Luo J. Ligand-independent androgen receptor variants derived from splicing of cryptic exons signify hormone-refractory prostate cancer. Cancer research. 2009;69(1):16-22. Epub 2009/01/02. doi: 10.1158/00085472.CAN-08-2764. PubMed PMID: 19117982; PubMed Central PMCID: PMC2614301.

2. $\mathrm{Hu} \mathrm{R}$, Isaacs WB, Luo J. A snapshot of the expression signature of androgen receptor splicing variants and their distinctive transcriptional activities. The Prostate. 2011;71(15):1656-67. Epub 2011/03/30. doi: 10.1002/pros.21382. PubMed PMID: 21446008; PubMed Central PMCID: PMC3360954.

3. Hu R, Lu C, Mostaghel EA, Yegnasubramanian S, Gurel M, Tannahill C, Edwards J, Isaacs W, Nelson PS, Bluemn E, Plymate SR, Luo J. Distinct transcriptional programs mediatd by the ligand-dependent full-length androgen receptor and its splice variants in castration-resistant prostate cancer. Cancer research. 2012;accepted.

4. Antonarakis ES, Lu C, Wang H, Luber B, Nakazawa M, Roeser JC, Chen Y, Mohammad TA, Chen Y, Fedor HL, Lotan TL, Zheng Q, De Marzo AM, Isaacs JT, Isaacs WB, Nadal R, Paller CJ, Denmeade SR, Carducci MA, Eisenberger MA, Luo J. AR-V7 and resistance to enzalutamide and abiraterone in prostate cancer. The New England journal of medicine. 2014;371(11):1028-38. Epub 2014/09/04. doi: 10.1056/NEJMoa1315815. PubMed PMID: 25184630; PubMed Central PMCID: PMC4201502.

5. Plymate SR, Luo J. The Expression Signature of Androgen Receptor Splice Variants and Their Distinctive Transcriptional Activities in Castration-Resistant Prostate Cancer. Androgen-Responsive Genes in Prostate Cancer: Springer; 2013. p. 201-13. 
6. Nakazawa M, Antonarakis ES, Luo J. Androgen receptor splice variants in the era of enzalutamide and abiraterone. Hormones \& cancer. 2014;5(5):265-73. Epub 2014/07/23. doi: 10.1007/s12672-014-0190-1. PubMed PMID: 25048254; PubMed Central PMCID: PMC4167475.

\section{$\underline{\text { Appendix }}$}

A recent study published in New England Journal of Medicine (41 pages in total including supplemental data). 
ORIGINAL ARTICLE

\section{AR-V7 and Resistance to Enzalutamide and Abiraterone in Prostate Cancer}

\author{
Emmanuel S. Antonarakis, M.D., Changxue Lu, Ph.D., Hao Wang, Ph.D., \\ Brandon Luber, Sc.M., Mary Nakazawa, M.H.S., Jeffrey C. Roeser, B.S., \\ Yan Chen, Ph.D., Tabrez A. Mohammad, Ph.D., Yidong Chen, Ph.D., \\ Helen L. Fedor, B.S., Tamara L. Lotan, M.D., Qizhi Zheng, M.D., \\ Angelo M. De Marzo, M.D., Ph.D., John T. Isaacs, Ph.D., William B. Isaacs, Ph.D., \\ Rosa Nadal, M.D., Channing J. Paller, M.D., Samuel R. Denmeade, M.D., \\ Michael A. Carducci, M.D., Mario A. Eisenberger, M.D., and Jun Luo, Ph.D.
}

A BSTRACT

\section{BACKGROUND}

The androgen-receptor isoform encoded by splice variant 7 lacks the ligand-binding domain, which is the target of enzalutamide and abiraterone, but remains constitutively active as a transcription factor. We hypothesized that detection of androgen-receptor splice variant 7 messenger RNA (AR-V7) in circulating tumor cells from men with advanced prostate cancer would be associated with resistance to enzalutamide and abiraterone.

\section{METHODS}

We used a quantitative reverse-transcriptase-polymerase-chain-reaction assay to evaluate AR-V7 in circulating tumor cells from prospectively enrolled patients with metastatic castration-resistant prostate cancer who were initiating treatment with either enzalutamide or abiraterone. We examined associations between AR-V7 status (positive vs. negative) and prostate-specific antigen (PSA) response rates (the primary end point), freedom from PSA progression (PSA progression-free survival), clinical or radiographic progression-free survival, and overall survival.

\section{RESULTS}

A total of 31 enzalutamide-treated patients and 31 abiraterone-treated patients were enrolled, of whom $39 \%$ and $19 \%$, respectively, had detectable AR-V7 in circulating tumor cells. Among men receiving enzalutamide, AR-V7-positive patients had lower PSA response rates than AR-V7-negative patients ( $0 \%$ vs. $53 \%, P=0.004)$ and shorter PSA progression-free survival (median, 1.4 months vs. 6.0 months; $\mathrm{P}<0.001$ ), clinical or radiographic progression-free survival (median, 2.1 months vs. 6.1 months; $\mathrm{P}<0.001$ ), and overall survival (median, 5.5 months vs. not reached; $\mathrm{P}=0.002$ ). Similarly, among men receiving abiraterone, AR-V7-positive patients had lower PSA response rates than AR-V7-negative patients $(0 \%$ vs. $68 \%, \mathrm{P}=0.004)$ and shorter PSA progression-free survival (median, 1.3 months vs. not reached; $\mathrm{P}<0.001$ ), clinical or radiographic progression-free survival (median, 2.3 months vs. not reached; $\mathrm{P}<0.001$ ), and overall survival (median, 10.6 months vs. not reached, $\mathrm{P}=0.006$ ). The association between AR-V7 detection and therapeutic resistance was maintained after adjustment for expression of full-length androgen receptor messenger RNA.

\section{CONCLUSIONS}

Detection of AR-V7 in circulating tumor cells from patients with castration-resistant prostate cancer may be associated with resistance to enzalutamide and abiraterone. These findings require large-scale prospective validation. (Funded by the Prostate Cancer Foundation and others.)
From the Departments of Oncology (E.S.A., H.W., B.L., J.T.I., R.N., C.J.P., S.R.D., M.A.C., M.A.E.), Pathology (H.L.F., T.L.L., Q.Z., A.M.D.M.), and Urology (C.L., M.N., J.C.R., Yan Chen, W.B.I., J.L.), Johns Hopkins University School of Medicine, Baltimore; and Greehey Children's Cancer Research Institute (T.A.M., Yidong Chen) and the Department of Epidemiology and Biostatistics (Yidong Chen), University of Texas Health Science Center at San Antonio, San Antonio. Address reprint requests to Dr. Antonarakis at the Prostate Cancer Research Program, Sidney Kimmel Comprehensive Cancer Center at Johns Hopkins, 1650 Orleans St., CRB1-1M45, Baltimore, MD 21287, or at eantonal@jhmi edu; or to Dr. Luo at the James Buchanan Brady Urological Institute and the Department of Urology, Johns Hopkins University School of Medicine, $600 \mathrm{~N}$. Wolfe St., Baltimore, MD 21287, or at jluol@ jhmi.edu.

This article was published on September 3, 2014, at NEJM.org.

DOI: 10.1056/NEJMoal315815 Copyright @ 2014 Massachusetts Medical Society. 
T $\mathrm{T}$ IS NOW ACCEPTED THAT CASTRATIONresistant prostate cancer is not androgenindependent and continues to rely on androgen signaling. ${ }^{1}$ Owing to this new understanding, several drugs have recently emerged for the treatment of castration-resistant prostate cancer; these agents either suppress the synthesis of extragonadal androgens or target the androgen receptor directly. ${ }^{2}$ Enzalutamide is an inhibitor of androgen-receptor signaling that exerts its activity by binding avidly to the ligand-binding domain of the androgen receptor, competing with and displacing the natural ligands of this receptor (testosterone and dihydrotestosterone) while also inhibiting translocation of the androgen receptor into the nucleus and impairing transcriptional activation of androgen-responsive target genes. ${ }^{3,4}$ Abiraterone is an inhibitor of cytochrome P450 17A1 (CYP17A1) that impairs androgen-receptor signaling by depleting adrenal and intratumoral androgens. ${ }^{5,6}$ After studies showed improved survival with these drugs, ${ }^{7-9}$ both agents were approved by the Food and Drug Administration for the treatment of metastatic castration-resistant prostate cancer.

Although enzalutamide and abiraterone represent breakthroughs in the treatment of metastatic castration-resistant prostate cancer, approximately 20 to $40 \%$ of patients have no response to these agents with respect to prostate-specific antigen (PSA) levels (i.e., they have primary resistance)..$^{4-9}$ Among patients who initially have a response to enzalutamide or abiraterone, virtually all eventually acquire secondary resistance. One plausible explanation for the resistance to both agents may involve the presence of androgenreceptor splice variants. ${ }^{10,11}$ These alternatively spliced variants encode a truncated androgenreceptor protein that lacks the $\mathrm{C}$-terminal ligand-binding domain but retains the transactivating $\mathrm{N}$-terminal domain. ${ }^{12,13}$ Although the resultant truncated proteins are unable to bind ligand, they are constitutively active as transcription factors and capable of promoting activation of target genes.

Because enzalutamide exerts its antitumor activity through its interaction with the ligand-binding domain of the androgen receptor, it would be expected that the presence of the protein encoded by the androgen-receptor variant (which lacks the ligand-binding domain) may be associated with enzalutamide resistance. Furthermore, this pro- tein is ligand-independent and yet constitutively active, and its activity would not be expected to be inhibited by ligand-depleting agents such as abiraterone. Although these hypotheses are supported by preclinical studies, ${ }^{10,11,14,15}$ the clinical significance of androgen-receptor variants in patients receiving enzalutamide or abiraterone is unknown.

To investigate the clinical relevance of androgen-receptor variants in castration-resistant prostate cancer, we prospectively evaluated androgenreceptor splice variant 7 messenger RNA (AR-V7) in circulating tumor cells from patients receiving enzalutamide or abiraterone. Although multiple androgen-receptor variants have been discovered, we focused on AR-V7 because it is the only known androgen-receptor variant encoding a functional protein product that is detectable in clinical specimens. ${ }^{13,16}$ We hypothesized that detection of AR-V7 in circulating tumor cells may be associated with resistance to enzalutamide and abiraterone in patients with castration-resistant prostate cancer.

\section{METHODS}

\section{PATIENTS}

We prospectively enrolled men with metastatic castration-resistant prostate cancer who were beginning standard-of-care treatment with enzalutamide or abiraterone. Patients were required to have histologically confirmed prostate adenocarcinoma, progressive disease despite "castration levels" of serum testosterone $(<50 \mathrm{ng}$ per deciliter [1.73 nmol per liter]) with continued androgendeprivation therapy, and documented metastases, as confirmed on computed tomography (CT) or bone scanning with technetium-99m-labeled methylene diphosphonate. Patients had to have three or more rising serum PSA values obtained 2 or more weeks apart, with the last value being $2.0 \mathrm{ng}$ per milliliter or higher - criteria for PSA progression that are consistent with Prostate Cancer Clinical Trials Working Group 2 (PCWG2) guidelines. ${ }^{17}$ Patients were excluded if they planned to receive additional concurrent anticancer therapies. Prior chemotherapy was permitted, as was previous treatment with the alternative agent directed at the androgen receptor (i.e., prior abiraterone use in enzalutamide-treated patients and vice versa). All enrolled patients provided written informed consent. 


\section{STUDY DESIGN AND ASSESSMENTS}

This was a prospective study evaluating the ability of baseline (pretreatment) AR-V7 status (positive vs. negative) in circulating tumor cells to predict a response or resistance to agents directed at the androgen receptor. The study was approved by the institutional review board at Johns Hopkins University. All the authors vouch for the completeness and integrity of the data and for the fidelity of the study to the clinical protocol (available with the full text of this article at NEJM.org). Peripheral-blood samples, for analysis of circulating tumor cells, were obtained from eligible patients at three prespecified time points: baseline, the time of a clinical or biochemical response (if a response occurred), and the time of clinical or radiographic progression. In addition, patients were encouraged to undergo core-needle biopsies of metastatic tumors at baseline and at the time of progression. Enzalutamide was given at a dose of $160 \mathrm{mg}$ daily; abiraterone was given at a dose of $1000 \mathrm{mg}$ daily, with prednisone at a dose of $5 \mathrm{mg}$ twice daily.

The times of follow-up assessments were prospectively defined: PSA measurements were obtained every 1 to 2 months, and CT of the chest, abdomen, and pelvis and technetium-99m bone scanning were performed every 2 to 4 months. Therapy with enzalutamide or abiraterone was continued until PSA progression, clinical or radiographic progression, or the occurrence of unmanageable drug-related toxic effects.

All the clinical investigators were unaware of the AR-V7 status of the participants. All the laboratory investigators were unaware of clinical information when determining AR-V7 status. The study statisticians were the first to unblind the data, after at least 30 patients had been enrolled per cohort.

\section{ANALYSIS OF CIRCULATING TUMOR CELLS AND TUMOR TISSUE}

Descriptions of the methods used for the capture of circulating tumor cells and of messenger RNA (mRNA) analysis for full-length androgen receptor and AR-V7 are provided in the Supplementary Appendix, available at NEJM.org. Quantitative reverse-transcriptase-polymerase-chain-reaction (RT-PCR) assays were used for mRNA detection.

The analysis of AR-V7 in metastatic tumor tissue is also described in the Supplementary Appendix. RNA in situ hybridization assays were used.

\section{CLINICAL OUTCOMES}

The primary end point was the proportion of patients with a PSA response $(\geq 50 \%$ decline in PSA level from baseline, maintained for $\geq 4$ weeks) at any time after the initiation of therapy; the end point was assessed separately for enzalutamidetreated patients and abiraterone-treated patients. The best PSA response (maximal percentage decrease in PSA level from baseline) for each patient was also determined.

Secondary end points were freedom from PSA progression (PSA progression-free survival), freedom from clinical or radiographic progression (clinical or radiographic progression-free survival), and overall survival. PSA progression was defined as an increase in the PSA level of $25 \%$ or more above the nadir (and by $\geq 2$ ng per milliliter), with confirmation 4 or more weeks later (PCWG2 criteria). ${ }^{17}$ Clinical or radiographic progression was defined as symptomatic progression (worsening disease-related symptoms or new cancer-related complications), radiographic progression $(\geq 20 \%$ increase in the sum of the diameters of soft-tissue target lesions on CT scanning [according to the Response Evaluation Criteria in Solid Tumors ${ }^{18}$ ] or $\geq 2$ new bone lesions on bone scanning), or death, whichever occurred first. ${ }^{17}$ Overall survival was defined as the time to death from any cause.

\section{STATISTICAL ANALYSIS}

Statistical analyses were performed separately in the enzalutamide and abiraterone cohorts. The sample size was determined on the basis of the primary end point of PSA response. We assumed that AR-V7 would be detectable from baseline samples of circulating tumor cells in $50 \%$ of enzalutamide-treated patients and $50 \%$ of abiraterone-treated patients. In both cohorts, we hypothesized that PSA response rates would be $10 \%$ or less in AR-V7-positive patients and $60 \%$ or more in AR-V7-negative patients. ${ }^{7,8}$ With this assumption, we calculated that a sample of 30 patients per cohort would give the study $85 \%$ power to detect a difference of 50 percentage points in PSA response rates (i.e., a rate of $10 \%$ in AR-V7-positive men and 60\% in AR-V7-negative men), with the use of a two-sided test at an alpha level of 0.10 .

In each cohort, clinical outcomes were compared between AR-V7-positive patients and AR- 
V7-negative patients. PSA response rates were compared with the use of Fisher's exact test. Time-to-event outcomes (i.e., PSA progressionfree survival, clinical or radiographic progressionfree survival, and overall survival) were evaluated with the use of Kaplan-Meier methods, and survival-time differences were compared with the use of the log-rank test. Univariate and multivariable Cox regressions were used to assess the effect of AR-V7 status on the prediction of timeto-event outcomes. Owing to the small sample size and the limited number of events, each multivariable model included only three variables (AR-V7 status, the level of expression of fulllength androgen receptor, and prior use of the alternative therapy directed at the androgen receptor), to prevent overfitting.

We also performed propensity-score-weighted multivariable Cox analyses for PSA progression-free survival and clinical or radiographic progression-free survival, in which the propensity score (the probability of being AR-V7-positive) was calculated from logistic regression with the use of variables including the Gleason score, the baseline PSA level, the number of prior hormonal treatments, the presence or absence of visceral metastases, the Eastern Cooperative Oncology Group (ECOG) score, prior use of abiraterone or enzalutamide, and the level of full-length androgen receptor. All tests were two-sided, and P values of 0.05 or less were considered to indicate statistical significance. Statistical analyses were performed with the use of $\mathrm{R}$ software, version 2.15.1.

\section{RESULTS}

\section{AR-V7 DETECTION IN CIRCULATING TUMOR CELLS}

We first demonstrated our ability to detect AR-V7 transcript in cells by looking for AR-V7 in normal human blood spiked with VCaP cells (Fig. S1A in the Supplementary Appendix), a prostate-cancer cell line known to express both full-length androgen receptor and AR-V7..13 We then assayed the patient samples; examples of positive and negative detection of AR-V7 in blood samples from two patients are shown in Figure S1B in the Supplementary Appendix. After the validity of the assay was established (not shown), AR-V7 positivity was defined as detection of the AR-V7 transcript by means of a quantitative RT-PCR assay at 36 or fewer PCR cycles, corresponding to detection of one or more copies of AR-V7 complementary DNA as determined by the relationship between cycle number and serial dilutions of prequantified AR-V7 (Fig. S2 in the Supplementary Appendix).

\section{PATIENT CHARACTERISTICS}

From December 2012 through September 2013, we prospectively enrolled 62 patients with detectable circulating tumor cells, of whom 31 received enzalutamide and 31 received abiraterone (Table S1 in the Supplementary Appendix). A total of 35 enzalutamide-treated men were screened to identify 31 with detectable circulating tumor cells (89\% yield); 36 abiraterone-treated men were screened to identify 31 with detectable circulating tumor cells ( $86 \%$ yield). The 9 men with no detectable circulating tumor cells were excluded from further analysis. The median follow-up time was 5.4 months (range, 1.4 to 9.9) among enzalutamide-treated patients and 4.6 months (range, 0.9 to 8.2 ) among abiraterone-treated patients. A total of $39 \%$ of enzalutamide-treated patients (12 of 31 patients) and 19\% of abiraterone-treated patients (6 of 31 patients) had detectable AR-V7 mRNA in baseline samples of circulating tumor cells. Among the 18 men with detectable AR-V7 from the entire study cohort, the median ratio of AR-V7 to full-length androgen receptor mRNA was $21.0 \%$ (range, 1.8 to 208.0) (Fig. 1); detection of AR-V7 was associated with increased expression of full-length androgen receptor mRNA $(\mathrm{P}<0.001)$.

In the enzalutamide cohort, AR-V7-positive patients had higher levels of full-length androgen receptor mRNA and PSA than did AR-V7negative patients and were more likely than AR-V7-negative patients to have an ECOG performance-status score of 1 or 2 (scores range from 0 to 5 , with 0 indicating no symptoms and higher scores indicating increasing disability), visceral metastases, and six or more bone metastases and to have had prior docetaxel treatment and prior abiraterone treatment (Table S1A in the Supplementary Appendix). A total of $55 \%$ of the patients who had previously received abiraterone (11 of 20 patients) had detectable AR-V7, as compared with $9 \%$ of the patients who had not previously received the drug ( 1 of 11 patients). Table S2A in the Supplementary Appendix shows clinical outcomes separately for patients who had previously received abiraterone and those who had not previously received the drug. 


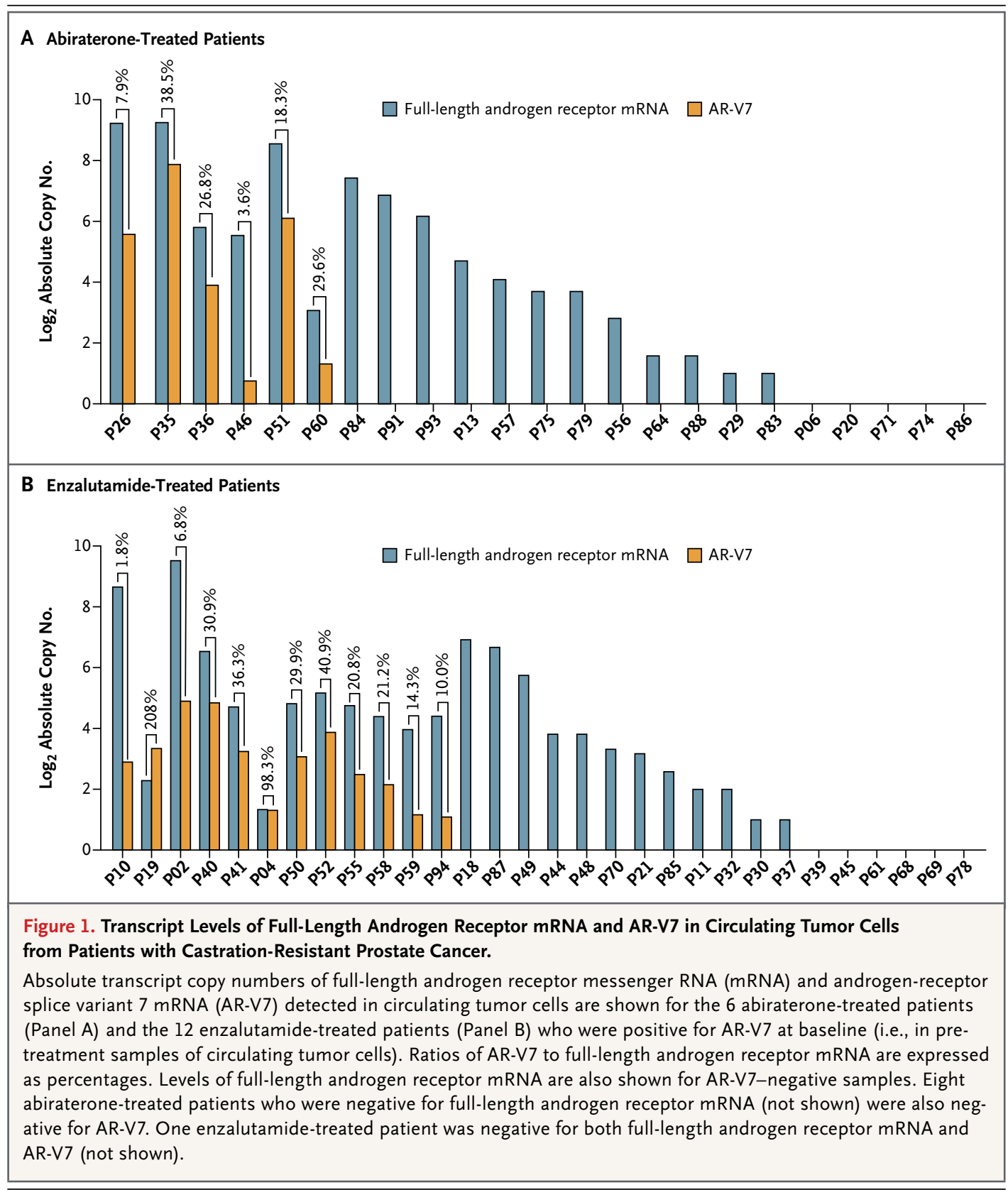

In the abiraterone cohort, AR-V7-positive patients had higher levels of full-length androgen receptor mRNA, PSA, and alkaline phosphatase, and a higher number of prior hormonal therapies than did AR-V7-negative patients and were more likely than AR-V7-negative patients to have an ECOG performance-status score of 1 or 2 and prior enzalutamide treatment (Table S1B in the Supplementary Appendix). A total of $50 \%$ of patients who had previously received enzalutamide ( 2 of 4 patients) had detectable AR-V7, as compared with $15 \%$ of patients who had not previously received the drug (4 of 27 patients). Table S2B in the Supplementary Appendix shows clinical outcomes separately for patients who had previously received enzalutamide and those who had not previously received the drug.

\section{PRIMARY END POINT}

The overall proportion of patients who had a PSA response while receiving enzalutamide was 32\% (95\% confidence interval [CI], 17 to 51; 10 of 31 
men). In the enzalutamide cohort, the PSA response rate among AR-V7-positive patients was $0 \%$ (95\% CI, 0 to 26 ; 0 of $12 \mathrm{men}$ ), and the rate among AR-V7-negative patients was 53\% (95\% CI, 29 to 76; 10 of 19 men; $P=0.004)$. The best PSA responses are shown in Figure 2A. In linear regres-

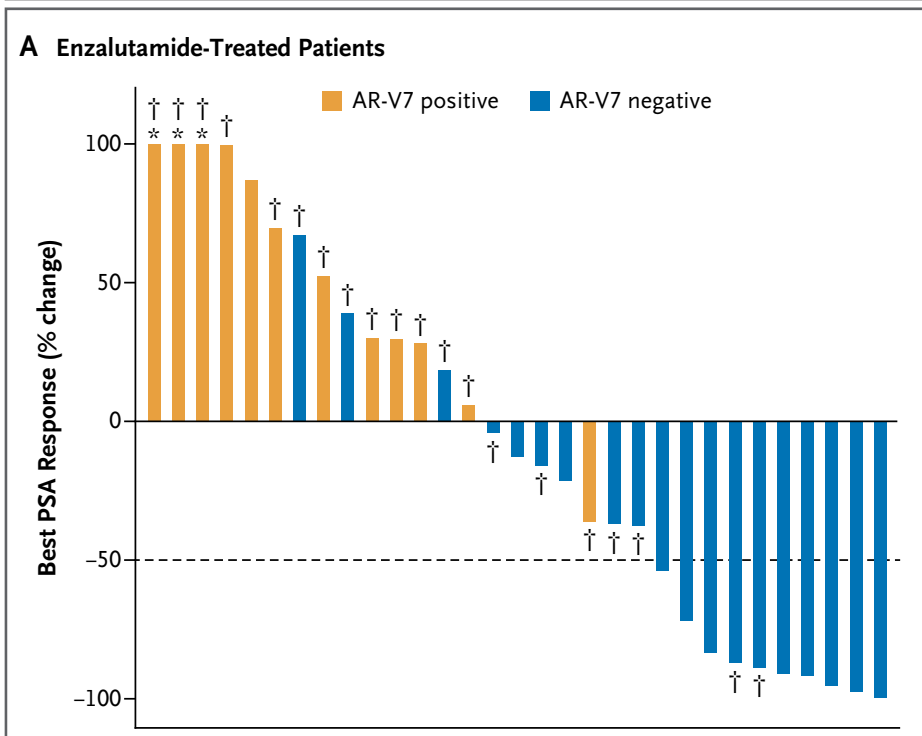

B Abiraterone-Treated Patients

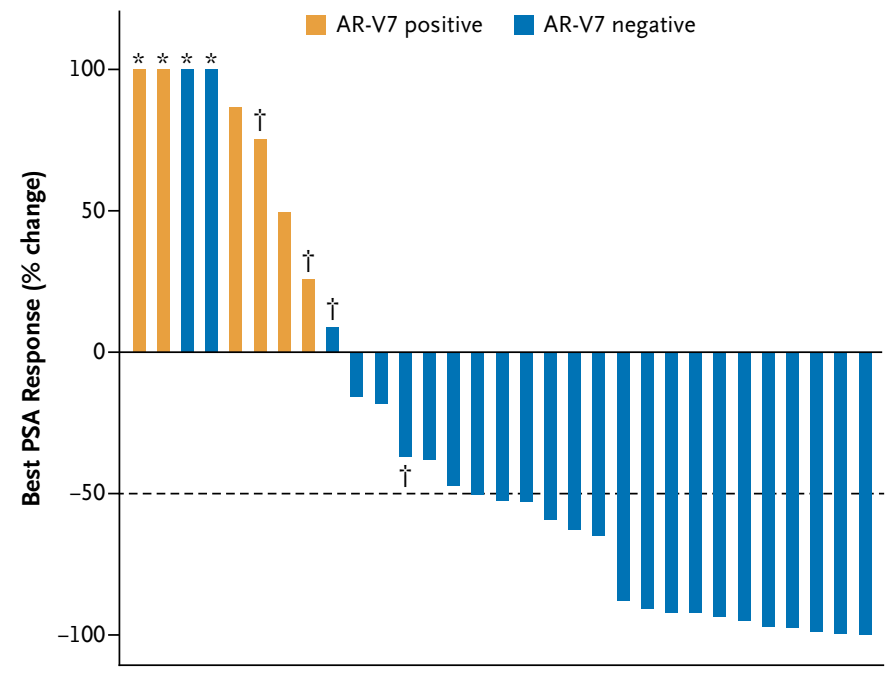

Figure 2. Waterfall Plots of Best Prostate-Specific Antigen (PSA) Responses According to AR-V7 Status.

Panel A shows the 31 enzalutamide-treated patients, and Panel B the 31 abiraterone-treated patients. The dotted line shows the threshold for defining a PSA response ( $\geq 50 \%$ reduction in PSA level from baseline). Asterisks indicate an increase of more than $100 \%$ in best PSA response. Daggers indicate patients in the enzalutamide cohort who had previously received abiraterone and patients in the abiraterone cohort who had previously received enzalutamide. sion modeling, AR-V7 status remained predictive of PSA response after adjustment for the expression of full-length androgen receptor mRNA $(\mathrm{P}<0.001)$.

The overall proportion of patients who had a PSA response while receiving abiraterone was $55 \%$ (95\% CI, 36 to $73 ; 17$ of 31 men). In the abiraterone cohort, the PSA response rate among AR-V7-positive patients was $0 \%$ (95\% CI, 0 to 46 ; 0 of 6 men), and the rate among AR-V7-negative patients was $68 \%$ (95\% CI, 46 to 85; 17 of 25 men; $P=0.004)$. The best PSA responses are shown in Figure 2B. In linear regression modeling, AR-V7 status remained predictive of PSA response after adjustment for the expression of full-length androgen receptor mRNA $(\mathrm{P}=0.02)$.

\section{SECONDARY END POINTS}

PSA Progression-free Survival

Among enzalutamide-treated patients, PSA progression-free survival was shorter among men with detectable AR-V7 at baseline than among those with undetectable AR-V7 ( $\mathrm{P}<0.001$ in a univariate analysis) (Fig. 3A). In a multivariable Cox model adjusted for the expression of full-length androgen receptor mRNA and prior abiraterone use, the detection of AR-V7 remained independently predictive of shorter PSA progression-free survival (hazard ratio for PSA progression, 3.1; 95\% CI, 1.0 to 9.2; $\mathrm{P}=0.046$ ); the level of fulllength androgen receptor mRNA was also predictive of shorter PSA progression-free survival (hazard ratio, 1.4; 95\% CI, 1.0 to 1.9), but previous abiraterone use was not (hazard ratio, 2.5; $95 \%$ CI, 0.4 to 14.5). Results of the propensityscore-weighted multivariable model are shown in Table S3A in the Supplementary Appendix.

Among abiraterone-treated patients, PSA progression-free survival was shorter among men with detectable AR-V7 at baseline than among those with undetectable AR-V7 $(\mathrm{P}<0.001$ in a univariate analysis) (Fig. 3B). In a multivariable Cox model adjusted for the expression of fulllength androgen receptor mRNA and prior enzalutamide use, the detection of AR-V7 was the only independent predictor of shorter PSA progression-free survival (hazard ratio for PSA progression, 15.7; 95\% CI, 2.1 to $117.5 ; \mathrm{P}=0.007$ ); neither the level of full-length androgen receptor mRNA (hazard ratio, $1.0 ; 95 \%$ CI, 0.8 to 1.2 ) nor previous enzalutamide use (hazard ratio, 0.9; 95\% CI, 0.1 to 5.2) was predictive. Results of the propensity-score-weighted multivariable model 


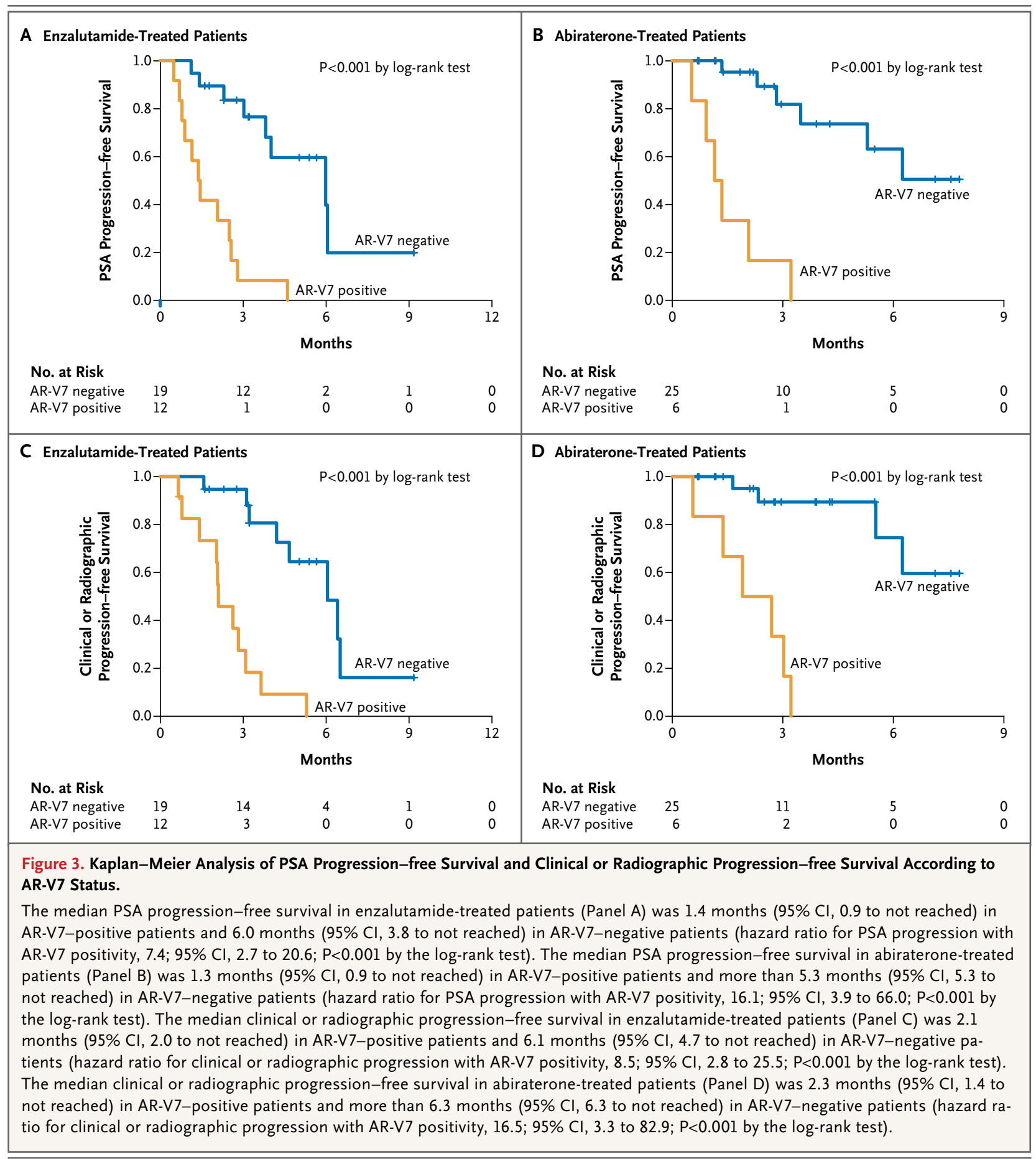

are shown in Table S3C in the Supplementary Appendix.

Clinical or Radiographic Progression-free Survival Among enzalutamide-treated patients, clinical or radiographic progression-free survival was short- er among men with detectable AR-V7 at baseline than among those with undetectable AR-V7 ( $\mathrm{P}<0.001$ in a univariate analysis) (Fig. $3 \mathrm{C}$ ). In a multivariable Cox model adjusted for the expression of full-length androgen receptor mRNA and prior abiraterone use, the detection of AR-V7 re- 
mained marginally predictive of shorter clinical or radiographic progression-free survival (hazard ratio for clinical or radiographic progression, 3.0; 95\% CI, 0.9 to 9.6; $\mathrm{P}=0.06$ ); the level of fulllength androgen receptor mRNA was also predictive (hazard ratio, 1.7; 95\% CI, 1.1 to 2.6 ), but previous abiraterone use was not (hazard ratio, 2.6; $95 \%$ CI, 0.2 to 27.6). Table S3B in the Supplementary Appendix shows the results of the propensity-score-weighted multivariable model.

Among abiraterone-treated patients, clinical or radiographic progression-free survival was shorter among men with detectable AR-V7 at baseline than among those with undetectable AR-V7 $(\mathrm{P}<0.001$ in a univariate analysis) (Fig. 3D). In a multivariable Cox model adjusted for the expression of full-length androgen receptor mRNA and prior enzalutamide use, the detection of AR-V7 was the only factor that was independently predictive of shorter clinical or radiographic progression-free survival (hazard ratio for clinical or radiographic progression, 7.6; 95\% CI, 1.0 to 57.6; $\mathrm{P}=0.05$ ); the level of full-length androgen receptor mRNA (hazard ratio, 1.1; 95\% CI, 0.9 to 1.5) and previous enzalutamide use (hazard ratio, 1.9; $95 \%$ CI, 0.4 to 10.0 ) were not predictive. Table S3D in the Supplementary Appendix shows the results of the propensity-score-weighted multivariable model.

\section{Overall Survival}

A preliminary survival analysis was conducted at $32 \%$ maturity in the enzalutamide-treated cohort (i.e., after $32 \%$ of the patients [10 patients] had died) (median follow-up, 8.4 months) and at 16\% maturity in the abiraterone-treated cohort (i.e., after $16 \%$ of the patients [ 5 patients] had died) (median follow-up. 9.3 months). Overall survival was shorter in men with detectable AR-V7 at baseline than among those with undetectable AR-V7 both in the enzalutamide cohort (median, 5.5 months vs. not reached; hazard ratio for death, $6.9 ; 95 \% \mathrm{CI}, 1.7$ to $28.1 ; \mathrm{P}=0.002$ by the log-rank test) (Fig. S3A in the Supplementary Appendix) and in the abiraterone cohort (median, 10.6 months vs. not reached; hazard ratio for death, $12.7 ; 95 \%$ CI, 1.3 to $125.3 ; \mathrm{P}=0.006$ by the log-rank test) (Fig. S3B in the Supplementary Appendix). Owing to the small number of events in each cohort, multivariable models were not constructed.

\section{COMBINED ANALYSIS}

As an exploratory analysis, we evaluated PSA responses, PSA progression-free survival, clinical or radiographic progression-free survival, and overall survival in the combined patient population of all 62 participants. The effect of AR-V7 status on these outcomes remained significant (Fig. S4 in the Supplementary Appendix).

\section{CONVERSION FROM AR-V7-NEGATIVE TO AR-V7- POSITIVE STATUS}

Of 42 men with undetectable AR-V7 at baseline who had at least one follow-up sample available, 6 patients (4 receiving enzalutamide and 2 receiving abiraterone) subsequently converted to AR-V7positive status during the course of treatment. All 16 patients with detectable AR-V7 at baseline who had at least one follow-up sample available remained AR-V7-positive during treatment. Clinical outcomes for all patients according to AR-V7 conversion status are summarized in Table S4 in the Supplementary Appendix. Changes in levels of AR-V7 expression during the course of treatment are summarized in Figure S5 in the Supplementary Appendix.

\section{TISSUE-BASED ANALYSES}

Seven patients consented to additional tissue-based studies: five underwent biopsies of metastatic tumors, and two consented to allow research autopsies to be performed after their death. Three of the seven patients had detectable AR-V7 in circulating tumor cells; these three patients also had detectable AR-V7 in metastatic tumor tissue according to RNA in situ hybridization analysis (Fig. 4). In addition, AR-V7 and full-length androgen receptor were detected at the protein level with the use of Western blot analysis in these patients (Fig. S7 in the Supplementary Appendix). Conversely, none of the four patients with undetectable AR-V7 in circulating tumor cells had detectable AR-V7 in metastatic tissue on RNA in situ hybridization, a finding that suggests good concordance. Finally, sequencing of the AR transcript with the use of RNA sequencing in metastatic lesions from two AR-V7-positive patients (autopsy specimens) did not identify mutations in the androgen-receptor gene that could explain resistance but did confirm the presence of AR-V7 splice junctions in both patients (Fig. S9 in the Supplementary Appendix). 
RELATIONSHIP BETWEEN FULL-LENGTH ANDROGEN RECEPTOR MRNA AND AR-V7

In all patients with detectable AR-V7, full-length androgen receptor mRNA was also expressed and at higher levels (with one exception) than the levels of AR-V7; increased expression of AR-V7 was generally (but not always) coupled with that of full-length androgen receptor mRNA (Fig. 1). Although expression of PSA (an indicator of canonical androgen-receptor signaling) was generally suppressed in AR-V7-negative patients during treatment with enzalutamide or abiraterone, PSA expression did not decrease in post-treatment samples of circulating tumor cells from men with detectable AR-V7 at baseline (Fig. S8 in the Supplementary Appendix). This observation is consistent with continued androgen-receptor signaling despite potent inhibition of full-length androgen receptor when AR-V7 coexists with full-length androgen receptor and contrasts with previous findings from a cell-line model of prostate cancer. ${ }^{19}$

In addition, genomewide comparisons of two AR-V7-negative and two AR-V7-positive metastatic tumor samples by means of gene-set enrichment analysis of RNA sequencing data (Figs. S9 and S10 in the Supplementary Appendix) or by means of targeted analysis of a set of genes regulated by the canonical androgen receptor (Table $S 5$ in the Supplementary Appendix) revealed alterations consistent with a shift toward AR-V7-driven transcription in AR-V7-positive samples. Finally, the addition of AR-V7 status to regression models that included only levels of full-length androgen receptor mRNA resulted in significant improvements in model fit across all clinical outcomes evaluated, confirming the added value of AR-V7 status in predicting outcomes with enzalutamide or abiraterone (Table S6 in the Supplementary Appendix).

\section{DISCUSSION}

Enzalutamide and abiraterone, two new therapies directed at the androgen receptor, represent important advances in the management of castration-resistant prostate cancer. ${ }^{4,7-9}$ However, a proportion of men do not benefit from these agents, and a clearer understanding of the mechanisms underlying resistance to these drugs would facilitate selection of alternative therapies

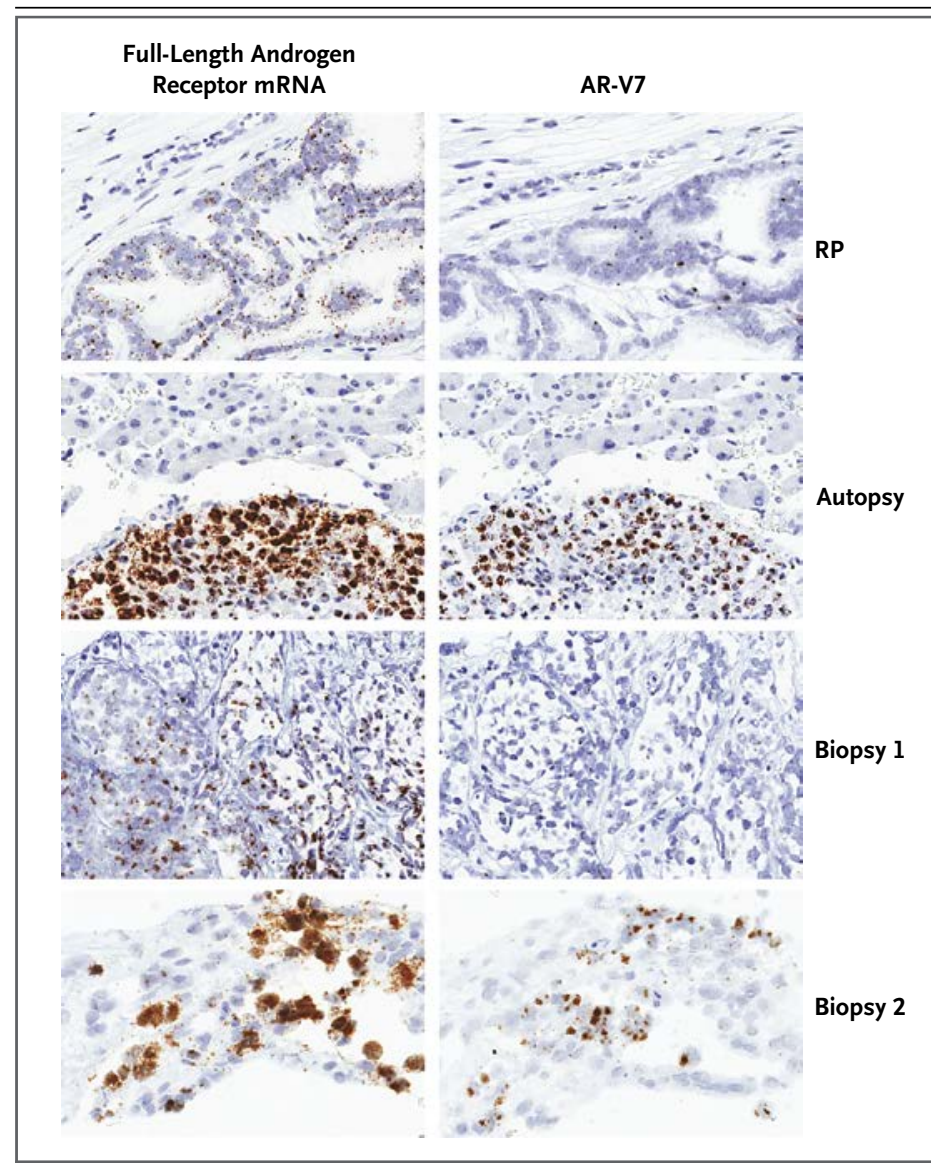

Figure 4. Detection of Full-Length Androgen Receptor mRNA and AR-V7 in Metastatic Prostate-Cancer Tissue.

In situ detection of full-length androgen receptor mRNA and AR-V7 in prostate-cancer tumor specimens was performed with the use of RNA in situ hybridization analysis. The tumor-tissue specimens shown are a radical-prostatectomy (RP) specimen that lacks AR-V7 expression from a patient (not enrolled in this study) who had not received hormonal treatment, an autopsy-derived specimen of a liver metastasis from a patient whose circulating tumor cells were shown to express AR-V7 (Autopsy), and core-needle biopsy specimens from a patient in whom AR-V7 was not detected (Biopsy 1) and a patient in whom AR-V7 was detected (Biopsy 2) in circulating tumor cells. All the tumor specimens show expression of fulllength androgen receptor mRNA. The prostate-cancer cell lines that served as positive and negative controls for AR-V7 detection by means of RNA in situ hybridization are shown in Figure 56 in the Supplementary Appendix.

(e.g., chemotherapies) for such patients. We found that AR-V7 can be detected reliably from circulating tumor cells and that detection of ARV7 in tumor cells appears to be associated with resistance to both enzalutamide and abiraterone. This conceptually simple model is biologically plausible, because the protein encoded by AR-V7 lacks the ligand-binding domain of the androgen 
receptor (the direct target of enzalutamide and the indirect target of abiraterone) while remaining constitutively active as a transcription factor in a ligand-independent manner. ${ }^{13,16}$

In our study, no AR-V7-positive patient had any appreciable clinical benefit from enzalutamide or abiraterone therapy. Moreover, although AR-V7 detection was associated with increased expression of full-length androgen receptor mRNA, the prognostic effect of AR-V7 was maintained after adjustment for levels of full-length androgen receptor mRNA. Finally, although prior treatment with abiraterone or enzalutamide was associated with AR-V7 positivity, AR-V7 status remained prognostic after adjustment for this factor. Therefore, the current study shows a strong association between the presence of AR-V7 and resistance to enzalutamide and abiraterone. If this finding is substantiated by others, it is possible that AR-V7 could be used as a biomarker to predict resistance to enzalutamide and abiraterone and to facilitate treatment selection. However, our study does not prove a causal role for AR-V7 in mediating resistance to enzalutamide or abiraterone, and it remains possible that AR-V7 is a marker of more advanced disease or a higher disease burden.

Preclinical studies have shown that androgenreceptor variants are much more common in castration-resistant prostate cancer than in hormone-sensitive prostate cancer, ${ }^{13}$ that they represent one potential mechanism driving the emergence of the castration-resistant phenotype, ${ }^{10}$ and that they may be responsible for the progression of castration-resistant prostate cancer. ${ }^{14}$ Studies involving patients with castration-resistant prostate cancer have shown that androgenreceptor variants are often expressed in metasta$\operatorname{ses}^{20,21}$ and that high levels of these variants in metastatic tissue are associated with faster disease progression and shorter cancer-specific survival than are low or undetectable levels. ${ }^{13,16,20}$ However, all these studies have been retrospective in nature, and none have obtained serial specimens across time or investigated the clinical significance of androgen-receptor variants in patients receiving enzalutamide or abiraterone.

Several studies have shown that although the protein isoforms encoded by androgen-receptor splice variants are constitutively active, their function may be dependent on the activity of full- length androgen receptor. ${ }^{19}$ Therefore, despite the fact that the protein isoforms encoded by androgen-receptor splice variants cannot be targeted directly by currently available drugs, it has been hypothesized that inhibition of full-length androgen receptor by enzalutamide or abiraterone could partially reverse resistance mediated by androgen-receptor variants. Our clinical data do not support this claim, because we did not observe any PSA responses in men harboring AR-V7 (all of whom also expressed full-length androgen receptor mRNA). An alternative treatment approach for AR-V7-positive patients would be to design agents targeting the $\mathrm{N}$-terminal domain of the androgen receptor, ${ }^{22-24}$ which would theoretically inhibit both full-length androgen receptor and androgen-receptor isoforms that lack the ligand-binding domain; such inhibitors are in early stages of drug development. ${ }^{23,24}$

There are likely to be multiple additional explanations for primary or acquired resistance to enzalutamide and abiraterone. For instance, overexpression of CYP17A1 (or other steroidogenic enzymes) leading to increased synthesis of intracrine or paracrine androgens has been shown to occur in patients receiving these agents. ${ }^{25-28}$ In addition, point mutations affecting the ligandbinding domain of the androgen receptor have been shown to confer agonistic activity to enzalutamide. ${ }^{29,30}$ Furthermore, expression of androgenregulated genes may be driven by alternative steroid receptors, such as the glucocorticoid receptor. $^{31,32}$ Finally, inhibition of the androgen receptor may lead to reciprocal up-regulation of other oncogenic pathways, such as the PI3KAKT pathway. ${ }^{33}$ It is unlikely that all cases of enzalutamide or abiraterone resistance will be explained by a single cause.

In conclusion, our data support an association between AR-V7 and resistance to both enzalutamide and abiraterone in patients with castration-resistant prostate cancer. These findings require large-scale prospective validation.

\footnotetext{
Supported by a Prostate Cancer Foundation (PCF) Young Investigator Award (to Dr. Antonarakis), a PCF Challenge Award, grants from the Department of Defense Prostate Cancer Research Program (W81XWH-10-2-0056 and W81XWH-10-2-0046, to the Prostate Cancer Biorepository Network [PCBN]; and W81XWH-12-1-0605, to Dr. Luo), a Johns Hopkins Prostate Cancer Specialized Program of Research Excellence grant (P50 CA058236), and a grant from the National Institutes of Health (P30 CA006973).
} 
Disclosure forms provided by the authors are available with the full text of this article at NEJM.org.

We thank the entire PCBN team at Johns Hopkins University School of Medicine, including Drs. Bruce Trock and Karen Sfanos, for providing valuable input and organizational support; Drs. Carla Ellis, Christine Iacobuzio-Donahue, and Barbara
Crain for assistance with the research autopsies; Dr. Nate Brennen and Ms. Jessica Hicks for technical assistance; and Ms. Medha Darshan and Ms. Guifang Yan for assistance in preparing the cryostat sections; and the patients and their families who participated in this study.

\section{REFERENCES}

1. Longo DL. New therapies for castration-resistant prostate cancer. $\mathrm{N}$ Engl J Med 2010;363:479-81.

2. Ryan CJ, Tindall DJ. Androgen receptor rediscovered: the new biology and targeting the androgen receptor therapeutically. J Clin Oncol 2011;29:3651-8.

3. Tran C, Ouk S, Clegg NJ, et al. Development of a second-generation antiandrogen for treatment of advanced prostate cancer. Science 2009;324:787-90.

4. Scher HI, Beer TM, Higano CS, et al. Antitumour activity of MDV3100 in castration-resistant prostate cancer: a phase 1-2 study. Lancet 2010;375:1437-46.

5. O'Donnell A, Judson I, Dowsett M, et al. Hormonal impact of the 17alphahydroxylase/C(17,20)-lyase inhibitor abiraterone acetate (CB7630) in patients with pros tate cancer. Br J Cancer 2004;90:2317-25. 6. Attard G, Reid AH, Yap TA, et al. Phase I clinical trial of a selective inhibitor of CYP17, abiraterone acetate, confirms that castration-resistant prostate cancer commonly remains hormone driven. J Clin Oncol 2008;26:4563-71.

7. Scher HI, Fizazi K, Saad F, et al. Increased survival with enzalutamide in prostate cancer after chemotherapy. N Eng J Med 2012;367:1187-97.

8. de Bono JS, Logothetis CJ, Molina A, et al. Abiraterone and increased survival in metastatic prostate cancer. N Engl J Med 2011;364:1995-2005.

9. Ryan CJ, Smith MR, de Bono JS, et al. Abiraterone in metastatic prostate cancer without previous chemotherapy. N Engl J Med 2013;368:138-48.

10. Nadiminty N, Tummala R, Liu C, et al. NF- $\kappa \mathrm{B} 2 / \mathrm{p} 52$ induces resistance to enzalutamide in prostate cancer: role of androgen receptor and its variants. Mol Cancer Ther 2013;12:1629-37.

11. Mostaghel EA, Marck BT, Plymate SR et al. Resistance to CYP17A1 inhibition with abiraterone in castration-resistant prostate cancer: induction of steroidogenesis and androgen receptor splice variants. Clin Cancer Res 2011;17:5913-25.

12. Dehm SM, Schmidt LJ, Heemers HV Vessella RL, Tindall DJ. Splicing of a novel androgen receptor exon generates a constitutively active androgen receptor that mediates prostate cancer therapy resistance. Cancer Res 2008;68:5469-77.

13. Hu R, Dunn TA, Wei S, et al. Ligandindependent androgen receptor variants derived from splicing of cryptic exons signify hormone-refractory prostate cancer. Cancer Res 2009;69:16-22.

14. Hu R, Lu C, Mostaghel EA, et al. Distinct transcriptional programs mediated by the ligand-dependent full-length androgen receptor and its splice variants in castration-resistant prostate cancer. Cancer Res 2012;72:3457-62.

15. Li Y, Chan SC, Brand LJ, Hwang TH, Silverstein KA, Dehm SM. Androgen receptor splice variants mediate enzalutamide resistance in castration-resistant prostate cancer cell lines. Cancer Res 2013;73:483-9.

16. Guo Z, Yang X, Sun F, et al. A novel androgen receptor splice variant is upregulated during prostate cancer progression and promotes androgen depletionresistant growth. Cancer Res 2009;69: 2305-13.

17. Scher HI, Halabi S, Tannock I, et al. Design and end points of clinical trials for patients with progressive prostate cancer and castrate levels of testosterone: recommendations of the Prostate Cancer Clinical Trials Working Group. J Clin Oncol 2008;26:1148-59.

18. Therasse P, Arbuck SG, Eisenhauer EA, et al. New guidelines to evaluate the response to treatment in solid tumors: European Organization for Research and Treatment of Cancer, National Cancer Institute of the United States, National Cancer Institute of Canada. J Natl Cancer Inst 2000;92:205-16.

19. Watson PA, Chen YF, Balbas MD, et al. Constitutively active androgen receptor splice variants expressed in castrationresistant prostate cancer require fulllength androgen receptor. Proc Natl Acad Sci U S A 2010;107:16759-65.

20. Hörnberg E, Ylitalo EB, Crnalic S, et al. Expression of androgen receptor splice variants in prostate cancer bone metastases is associated with castration-resistance and short survival. PLoS One 2011; 6(4):e19059.

21. Zhang X, Morrissey C, Sun S, et al. Androgen receptor variants occur frequently in castration resistant prostate cancer metastases. PLoS One 2011;6(11): e27970.

22. Sadar MD. Small molecule inhibitors targeting the "Achilles' heel" of androgen receptor activity. Cancer Res 2011;71:120813.
23. Ravindranathan $\mathrm{P}$, Lee $\mathrm{T}-\mathrm{K}$, Yang $\mathrm{L}$, et al. Peptidomimetic targeting of critical androgen receptor-coregulator interactions in prostate cancer. Nat Commun 2013;4:1923.

24. Andersen RJ, Mawji NR, Wang J, et al. Regression of castrate-recurrent prostate cancer by a small-molecule inhibitor of the amino-terminus domain of the androgen receptor. Cancer Cell 2010;17: 535-46.

25. Mitsiades N, Sung CC, Schultz N, et al. Distinct patterns of dysregulated expression of enzymes involved in androgen synthesis and metabolism in metastatic prostate cancer tumors. Cancer Res 2012; 72:6142-52.

26. Efstathiou E, Titus $M$, Wen $S$, et al. Molecular characterization of enzalutamide-treated bone metastatic castrationresistant prostate cancer. Eur Urol 2014 May 29 (Epub ahead of print).

27. Efstathiou E, Titus M, Tsavachidou D, et al. Effects of abiraterone acetate on androgen signaling in castrate-resistant prostate cancer in bone. J Clin Oncol 2012; 30:637-43.

28. Chang KH, Li R, Kuri B, et al. A gainof-function mutation in DHT synthesis in castration-resistant prostate cancer. Cell 2013;154:1074-84.

29. Balbas MD, Evans MJ, Hosfield DJ, et al. Overcoming mutation-based resistance to antiandrogens with rational drug design. eLife 2013;2:e00499.

30. Joseph JD, Lu N, Qian J, et al. A clinically relevant androgen receptor mutation confers resistance to second-generation antiandrogens enzalutamide and ARN509. Cancer Discov 2013;3:1020-9.

31. Sahu B, Laakso M, Pihlajamaa P, et al. FoxA1 specifies unique androgen and glucocorticoid receptor binding events in prostate cancer cells. Cancer Res 2013; 73:1570-80.

32. Arora VK, Schenkein E, Murali R, et al. Glucocorticoid receptor confers resistance to antiandrogens by bypassing androgen receptor blockade. Cell 2013;155: 1309-22.

33. Carver BS, Chapinski C, Wongvipat J, et al. Reciprocal feedback regulation of PI3K and androgen receptor signaling in PTEN-deficient prostate cancer. Cancer Cell 2011;19:575-86.

Copyright (c) 2014 Massachusetts Medical Society. 


\section{Supplementary Appendix}

This appendix has been provided by the authors to give readers additional information about their work.

Supplement to: Antonarakis ES, Lu C, Wang H, et al. AR-V7 and resistance to enzalutamide and abiraterone in prostate cancer. N Engl J Med. DOI: 10.1056/NEJMoa1315815 


\section{Supplementary Appendix}

\section{$\underline{\text { Table of Contents }}$}

1. METHODS (pages 2-6)

2. FIGURES [Figures S1-S10] (pages 7-20)

Figure S1. Detection of AR-V7 transcript in CTCs (page 7)

Figure S2. Justification for threshold of detection of AR-V7 (page 8)

Figure S3. Overall survival analysis stratified by AR-V7 status in enzalutamide-treated patients and abiraterone-treated patients (page 9)

Figure S4. Combined analysis of patient outcome by AR-V7 status (page 11)

Figure S5. Changes in AR-V7 and AR-FL transcript copy numbers detected in CTCs before and after treatment with enzalutamide and abiraterone (page 14)

Figure S6. Detection of AR-FL and AR-V7 using RNA-ISH in cell lines with known expression of AR-FL and AR-V7 (page 16)

Figure S7. Detection of AR-V7 at the protein level using Western blot analysis in patients with detectable AR-V7 transcript in CTCs (page 17)

Figure S8. Changes in expression levels of the PSA transcript before and after therapy with enzalutamide or abiraterone in men with baseline detectable AR-V7 (page 18)

Figure S9. RNA-Seq analysis of the AR transcript in two AR-V7-positive patients and two AR-V7-negative patients (page 19)

Figure S10. Gene set enrichment analysis of metastatic tumors from AR-V7-positive and AR-V7-negative patients (page 20)

3. TABLES [Tables S1-S6] (pages 21-28)

Table S1A. Baseline characteristics of the 31 patients treated with enzalutamide (page 21)

Table S1B. Baseline characteristics of the 31 patients treated with abiraterone (page 22)

Table S2. Clinical outcomes (PSA responses, PSA-PFS and PFS) reported separately according to prior exposure to abiraterone (in the enzalutamide cohort) and prior exposure to enzalutamide (in the abiraterone cohort) (page 23)

Table S3. Propensity score weighted multivariable Cox models adjusted for Gleason score, baseline PSA, number of prior hormonal treatments, presence of visceral metastases, ECOG score, prior abiraterone/enzalutamide use, and AR-FL levels (page 24)

Table S4. Clinical outcomes (PSA responses, PSA-PFS and PFS) for the entire patient population according to their AR-V7 'conversion' rates (page 25)

Table S5. Expression profiles of AR-regulated genes in AR-V7-positive and AR-V7negative metastatic tumors (page 26)

Table S6. R2 values for regression models that include only AR-FL levels (continuous variable) compared to regression models that additionally include AR-V7 status, for each clinical outcome (PSA response rate, PSA-PFS and PFS) (page 28)

4. REFERENCES (page 29) 


\section{Methods}

Analysis of circulating tumor cells

CTC analyses were conducted using the commercially-available AlereTM CTC AdnaTest platform (AdnaGen, Langenhagen, Germany). This assay does not enable CTC enumeration. Isolation and enrichment of CTCs was performed using the ProstateCancerSelect kit, and mRNA expression analyses were performed using the ProstateCancerDetect kit with multiplexed reverse-transcription polymerase-chain-reaction (qRT-PCR) primers to detect the presence of CTCs, and custom primers designed to detect the full-length-AR (AR-FL) and AR splice variant-7 (AR-V7). ${ }^{1,2}$ The relative AR-V7 transcript abundance was determined by calculating the ratio of AR-V7 to AR-FL. ${ }^{1,2}$ Additional details are provided below.

Blood samples were collected using standard BD Vacutainer ${ }^{\circledR}$ lavender top blood collection tubes (Becton Dickinson, Franklin Lakes, NJ) (Product \#: 367862) by venipuncture, and carried to the lab on ice. Laboratory processing was carried out within 2 hours of collection, according to instructions provided by the Alere ${ }^{\mathrm{TM}}$ CTC AdnaTest (Alere Inc., San Diego, CA). The AdnaTest is a CE-marked, RNA-based CTC enrichment and detection test with two components/kits. Briefly, the ProstateCancerSelect (Product No. T-1-520) kit was used to enrich CTC from $5 \mathrm{ml}$ blood using magnetic particles coated with a combination of antibodies recognizing prostate cancer cells, while the ProstateCancerDetect (Product No. T-1-521) kit was used to make cDNA for detection of prostate cancer-associated RNA transcripts using multiplexed polymerase chain reaction (PCR). On the basis of detection of PCR signals for PSA, PSMA, or EGFR (very rarely detected) by the Agilent Bioanalyzer (Agilent Technologies, Palo Alto, CA), CTC calls were made for each sample tested. The test was adapted for detection and quantification of AR-FL and AR-V7 by quantitative real-time PCR using custom primers specific for AR-FL (forward: 5'CAGCCTATTGCGAGAGAGCTG-3'， reverse: 5'-GAAAGGATCTTGGGCACTTGC-3') and AR-V7 (forward: conditions at $95^{\circ} \mathrm{C} \times 10 \mathrm{~s}, 58^{\circ} \mathrm{C} \times 30 \mathrm{~s}$, and $72^{\circ} \mathrm{C}$ x $30 \mathrm{~s}$ for 39 cycles followed by melting curve analysis. 
Standard dilution curves from known quantities of AR-FL and AR-V7 was generated for calculating absolute transcript copy numbers for AR-FL and AR-V7. Laboratory data was generated for each patient enrolled in the study in a blinded fashion and recorded into the master data sheet on a weekly basis. To rule out false positive and false negative findings, a number of quality control measures were implemented each time the assay was performed, including negative and positive controls at multiple levels for both CTC detection and AR quantification. This laboratory-developed RNA-based assay modified from a commercially available circulating tumor cell (CTC) detection platform was thoroughly evaluated and internally validated with standard quality measures implemented. First, all samples collected from healthy volunteers $(n=4)$ and CTC-negative CRPC patients $(n=9)$ were negative for AR-FL and AR-V7, excluding the possibility of false-positive detection due to contaminating leukocytes. Second, the test consistently detected both AR-FL and AR-V7 in normal blood samples spiked with 5 AR-V7 positive cells $(n=6)$. Third, overnight shipping of blood samples and storage of partially processed cell lysates (up to two weeks) did not compromise assay results (although our current study does not involving shipping). Fourth, all tests on clinical specimens were performed using a fraction (10\%) of the cDNA yield from $5 \mathrm{~mL}$ of blood, and were always accompanied by two negative and two positive controls. Detailed technical protocols will be made available upon request.

RNA in situ hybridization

RNA in situ hybridization (RISH) was performed to detect the androgen receptor (AR) and ARV7 using the ACD (Advanced cell Diagnostics, Hayward, CA) RNAscope 2.0 Brown kit. Briefly, formalin-fixed paraffin-embedded (FFPE) tissue or cell pellet blocks were sectioned and the slides baked for one hour at $60^{\circ} \mathrm{C}$. The slide were subsequently de-paraffinized with xylene for $20 \mathrm{~min}$ at room temperature, and allowed to air dry following two rinses using $100 \%$ ethanol. Following a series of pretreatment steps, the cells were permeablized using protease to allow probe access to the RNA target. ACD target probes, a series of paired oligonucleotides forming a binding site for a preamplifier, were custom designed to detect RNA corresponding to exon 1 of the human AR (ACD 401211), or the cryptic AR exon 3 sequence ${ }^{1,3}$ that encode human AR-V7 (ACD 401221). Hybridization of the probes to the AR 
RNA targets was performed by incubation in the oven for 2 hours at $40{ }^{\circ} \mathrm{C}$. Following two washes, the slides were processed for standard signal amplification steps per manufacturer's instructions.

\section{Western Blot}

Whole cell protein extracts were prepared from cultured prostate cancer cells or cryosections prepared from clinical specimens by using RIPA buffer (radioimmunoprecipitation assay buffer) (Cell Signaling Technology, Danvers, MA) supplemented with 1X protease inhibitors (Roche, Indianapolis, IN) and $1 \mathrm{X}$ phosphatase inhibitors (Thermo Fisher Scientific, Rockford, IL). Standard blots were prepared following electrophoresis of forty $\mu \mathrm{g}$ protein per sample on a $10 \%$ SDS-PAGE precast gel (BioRad Laboratories, Hercules, CA), and incubated overnight with anti-AR-V7 ${ }^{4}$ ( $\left.1 \mu \mathrm{g} / \mathrm{mL}\right)$, anti-AR (N20) (1:2000 dilution) (sc-816, Santa Cruz Biotechnology, Dallas, TX), anti-PSA (C-19) (1:500) (sc-7638, Santa Cruz Biotechnology), and anti- $\beta$-actin (1:5000 dilution) (Sigma, St Louis, MO). Following incubation with horseradish-peroxidase(HRP)-conjugated secondary antibodies, immunoreactive bands were visualized using the SuperSignal West Pico Chemiluminescent Substrate system (I-34080) (Thermo Fisher Scientific, Rockford, IL) on HyBlot CL film (E3022) (Denville Scientific, South Plainfield, NJ).

Prostate cancer cell lines

LNCaP cells (ATCC, Manassas, VA) were maintained in RPMI1640 medium (Invitrogen, Carlsbad, CA) with 10\% fetal bovine serum (FBS, Sigma-Aldrich, St. Louis, MO). LNCaP95 is an ARV7-positive androgen-independent cell line derived from the parental LNCaP cells as described previously ${ }^{4}$. LNCaP95 cells were maintained in phenol red-free RPMI 1640 medium supplemented with $10 \%$ charcoal stripped FBS (CSS). For analysis of androgen-induced changes in AR-V7, LNCaP95 cells were treated with R1881 (NEN, Waltham, MA) or ethanol vehicle control as described previously ${ }^{4}$. These cell lines were authenticated (DDC Medical, Fairfield, OH) using short tandem repeats DNA profiling and tested negative for mycoplasma. 
Metastatic prostate tumor tissue specimens

To investigate concordance in AR-V7 status between CTCs and tumor tissue, qRT-PCR analysis for AR-V7 was performed on fresh metastatic tumor biopsies (or autopsy specimens) from a subset of patients who consented to this. In addition, RNA in situ hybridization (RNA-ISH) was performed according to the manufacturer's instructions using the RNAscope platform (Advanced Cell Diagnostics, Hayward, CA) to visualize AR-V7 mRNA in formalin-fixed paraffin-embedded metastatic tumor tissues, and to correlate this with AR-V7 detection in CTCs. Additional details are provided below.

Research autopsies were performed on two patients who died during the course of treatment with enzalutamide. Both patients were AR-V7 positive as determined by the CTC assay before and after treatment. Metastatic prostate tumors were dissected and flash frozen blocks prepared. Following histological analysis, cryosections enriched for tumor cells were prepared following manual trimming of the frozen blocks, using a standard procedure as described previously ${ }^{5}$. High-quality total RNA in adequate quantity was extracted from two specimens (one from each patient) and labeled as AR-V7(+) Met1 and AR-V7(+) Met2, respectively. To identify relevant AR-V7-negative metastatic CRPC samples for comparison, we analyzed AR-FL and AR-V7 expression levels in a separate collection of CRPC specimens from men consented for autopsy (before the development of enzalutamide and abiraterone) as

described previously ${ }^{1,6,7}$. Two specimens that were AR-V7 negative but with AR-FL levels similar to those detected in other mCRPC specimens were identified from this collection of specimens. These two samples were labeled AR-V7(-) Met1 and AR-V7(-) Met2. Both samples were processed histologically in a similar fashion to enrich prostate carcinoma cells.

RNA-Seq analysis

Four metastatic prostate tissue specimens, AR-V7(+) Met1, AR-V7(+) Met2, AR-V7(-) Met1, and AR-V7(-) Met 2, were subjected to RNA-Seq following the standard TruSeq Stranded Total RNA Sample Prep Kit and sequenced using the Illumina HiSeq 2000 platform (Illumina Inc, San Diego, CA). We generated an average of $\sim 63$ million reads per sample. Sequences were aligned to UCSC hg19 genome build using TopHat, and mutation and splice junctions visualized using Integrated Genome 
Viewer (IGV) ${ }^{8}$. Read counts (gene expression levels) were obtained using HTSeq ${ }^{9}$, and normalized per kilo base-pair gene length and per million reads library size (RPKM). Fold expression changes (FC) between the two conditions (AR-V7(+) and AR-V7(-)) were calculated. Genes were pre-ranked by $\operatorname{logFC}$ and subjected to Gene Set Enrichment Analysis (GSEA) ${ }^{10}$. Both raw and processed RNA-Seq data were deposited in the Gene Expression Omnibus (accession number: GSE56701). 

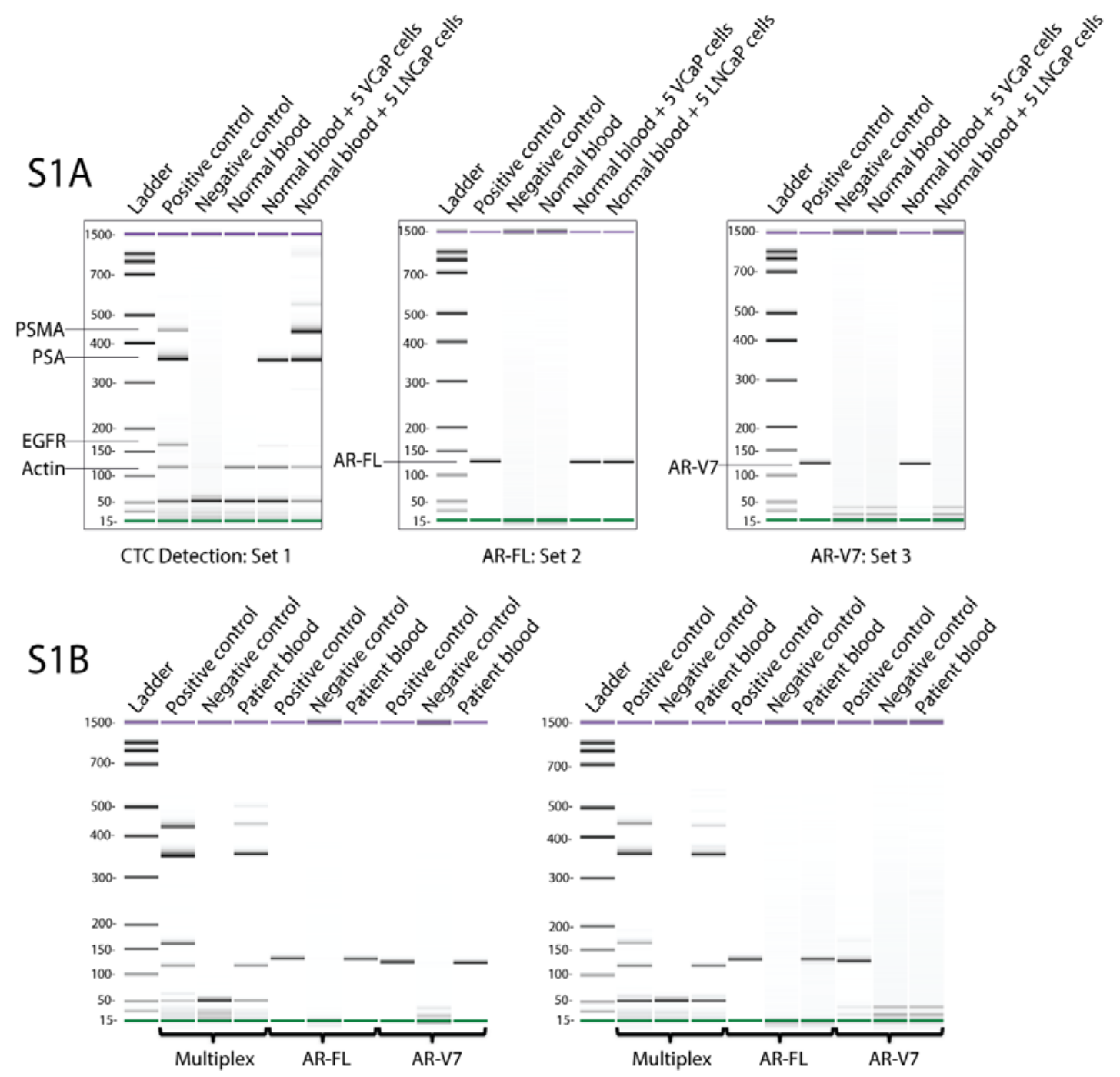

Figure S1. Detection of AR-V7 transcript in CTCs.

(A) Blood-based detection of full-length androgen receptor (AR-FL) and AR splice variant-7 (ARV7) transcripts in tumor cells spiked into $5 \mathrm{~mL}$ of blood from normal human volunteers. Following CTC capture, lysis, and cDNA synthesis, three sets of independent PCR reactions were performed to examine the presence of CTC-specific mRNA transcripts by multiplex PCR (set 1), as well as transcripts for AR-FL (set 2) and AR-V7 (set 3). (B) Examples of positive and negative detection of AR-V7 in baseline (pre-treatment) blood samples from two enzalutamide-treated patients. The patient in the left panel is positive for both AR-FL and AR-V7, while the patient in the right panel is positive only for AR-FL but negative for AR-V7. Both patients were positive for CTCs, as determined by the multiplex PCR assay (based on the examination of PSMA, PSA, EGFR and Actin) per the manufacturer's instructions provided by AdnaGen. 


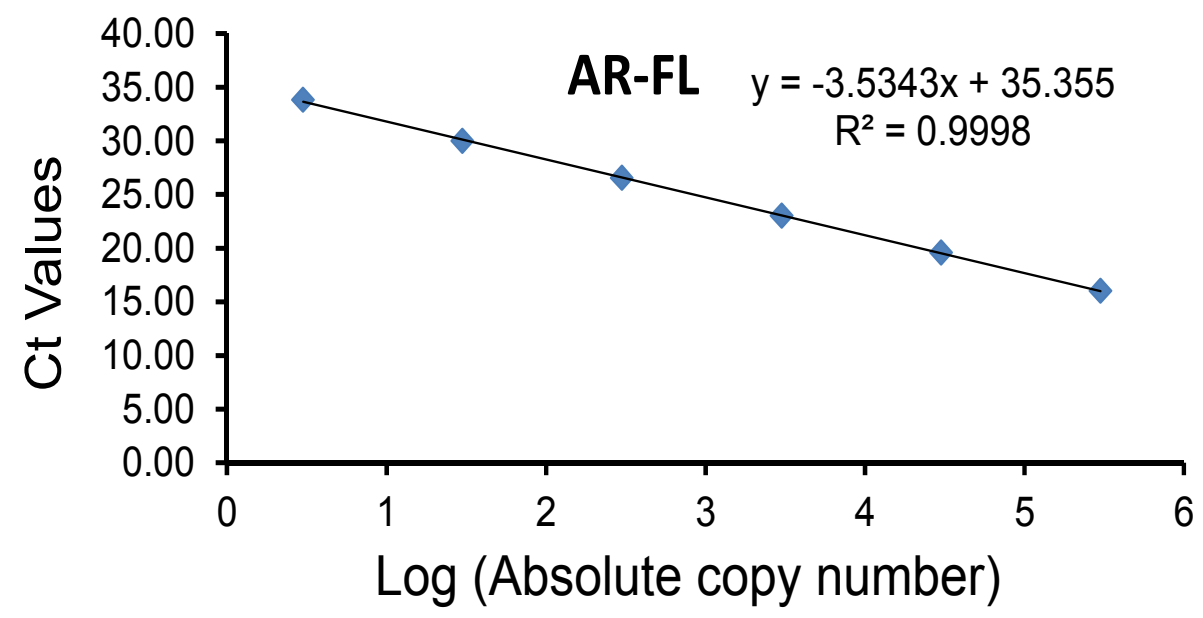

S2 B

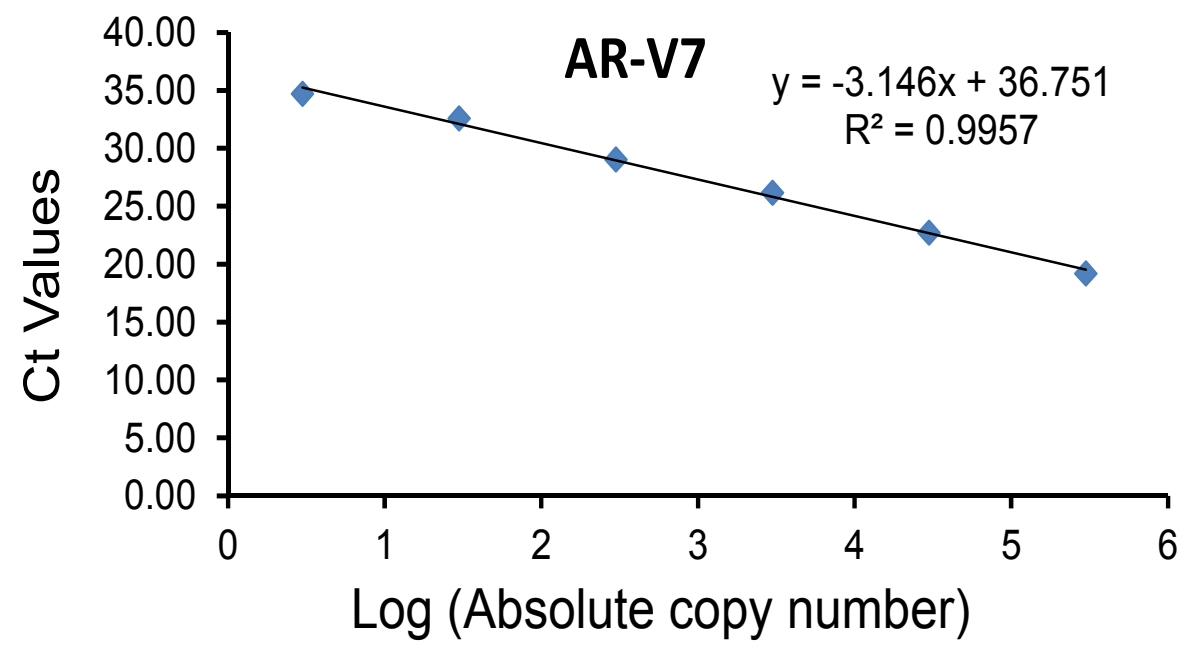

Figure S2. Justification for threshold of detection of AR-V7.

Standard dilution curves for AR-FL and AR-V7 are shown. Threshold cycle numbers (Y axis) in quantitative PCR reactions were determined for complementary DNA (cDNA) specific to AR-FL (A) and AR-V7 (B) at 6 dilutions containing the indicated number of copies of each transcript (X axis). Formulas were derived to quantify the absolute copy numbers on the basis of $\mathrm{Ct}$ values. 


\section{S3 A}

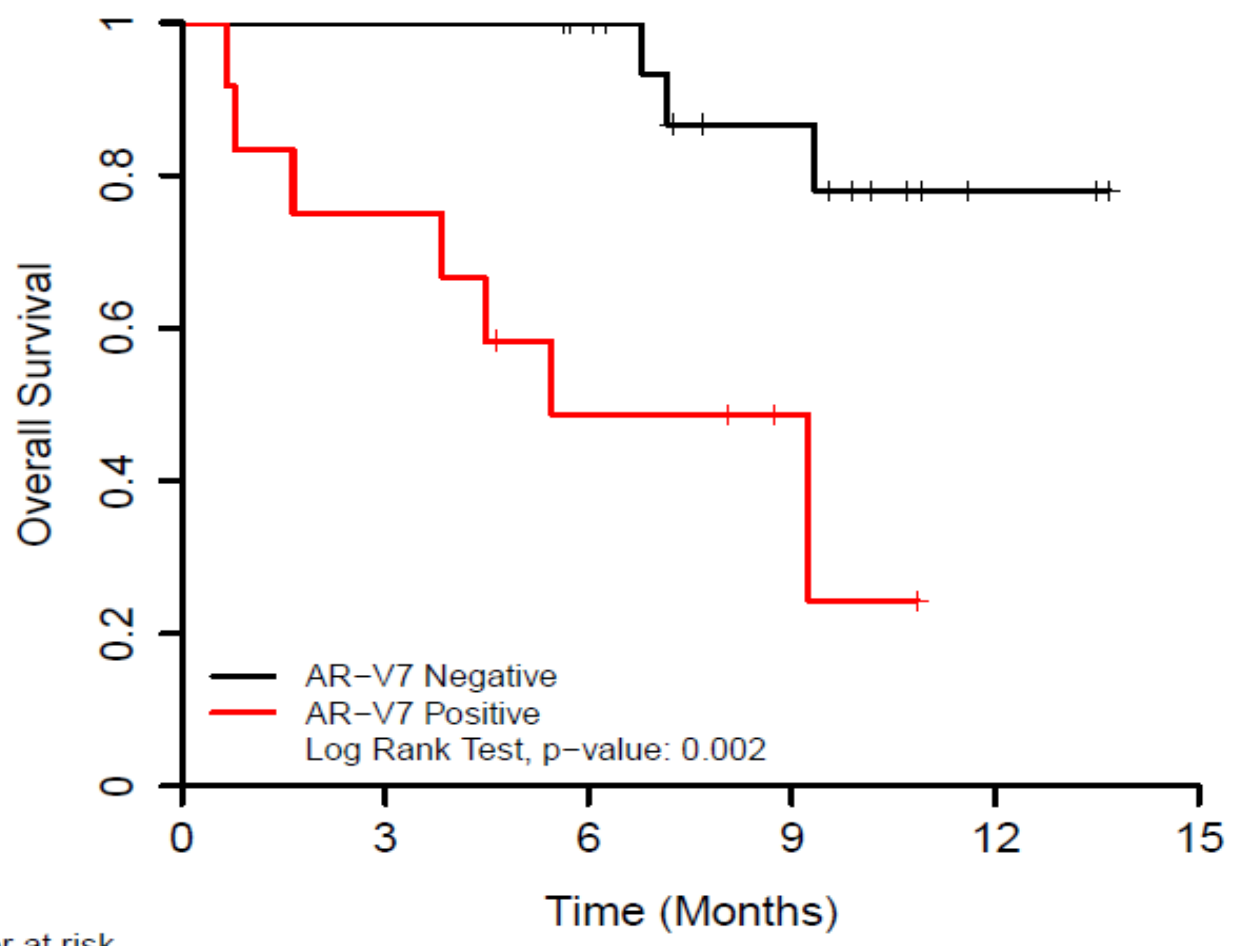

Number at risk

AR-V7 Negative: 19

AR-V7 Positive: 12

19

9

17

10

2

0

5

2

0

\section{S3 B}

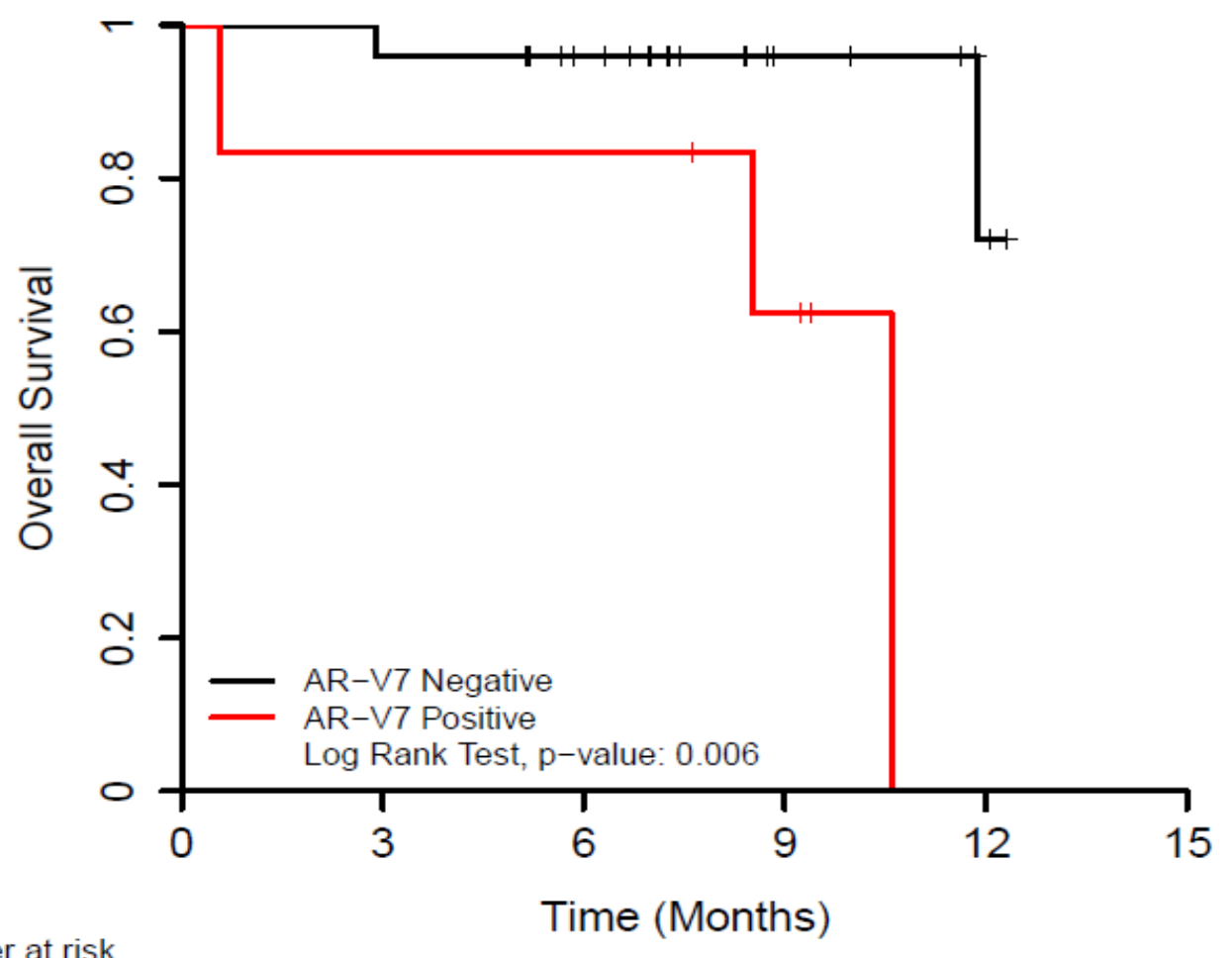

Number at risk

AR-V7 Negative: 25

AR-V7 Positive: 6

24

19

5

7

3

0

5

3

0 
Figure S3. Overall survival (OS) analysis stratified by AR-V7 status in enzalutamide-treated patients and abiraterone-treated patients.

(A) Median OS in enzalutamide-treated patients was 5.5 months $(95 \% \mathrm{CI}, 3.9-$ not reached) and not reached (95\%CI, not reached-not reached) in AR-V7-positive and AR-V7-negative patients, respectively (HR 6.9, 95\%CI 1.7-28.1, log-rank $P=0.002$ ).

(B) Median OS in abiraterone-treated patients was 10.6 months $(95 \% \mathrm{CI}, 8.5$-not reached) and $>11.9$ months $(95 \% \mathrm{CI}, 11.9-$ not reached) in AR-V7-positive and AR-V7-negative patients, respectively (HR 12.7, 95\%CI 1.3-125.3, log-rank $P=0.006)$. 
S4 A

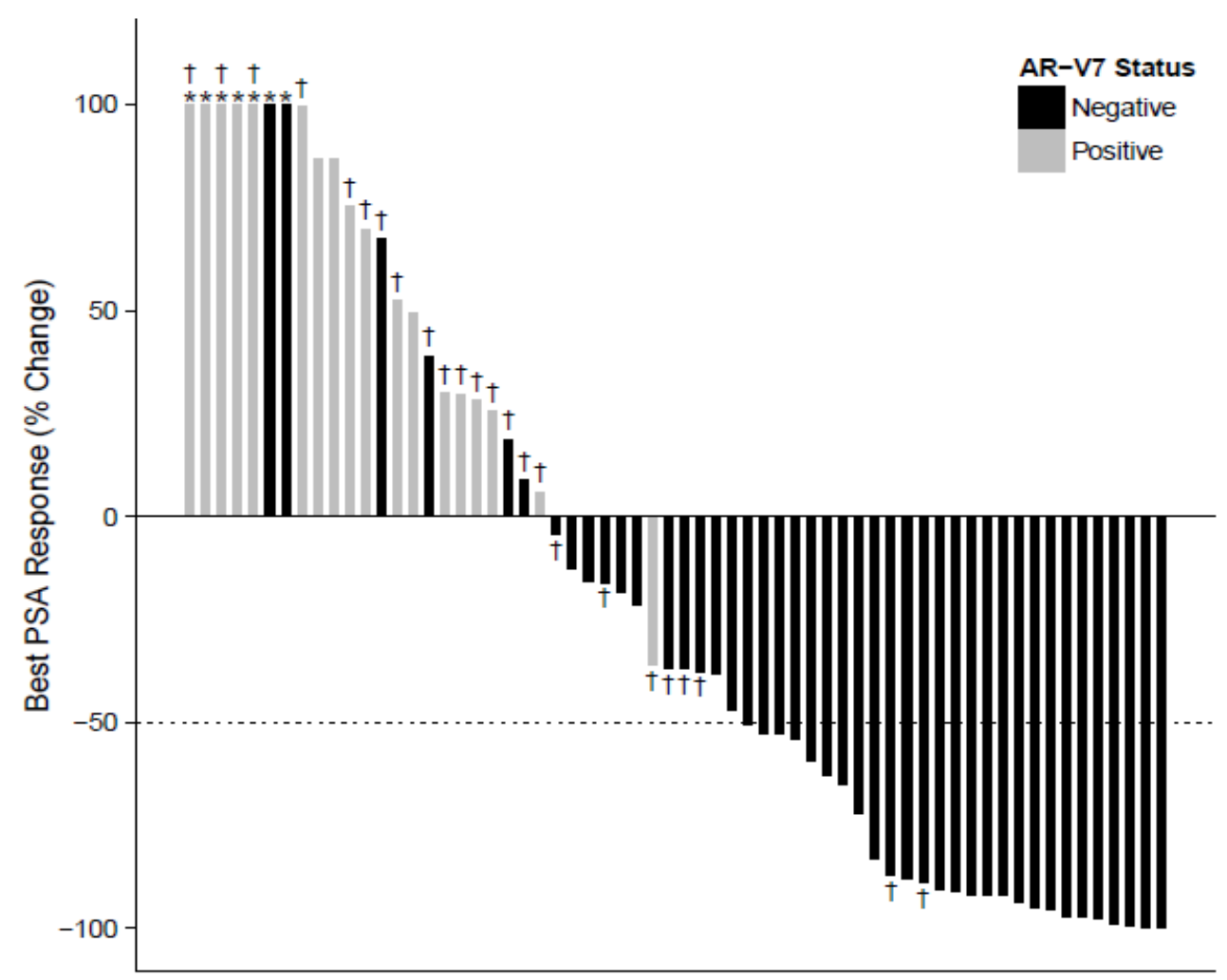

S4 B

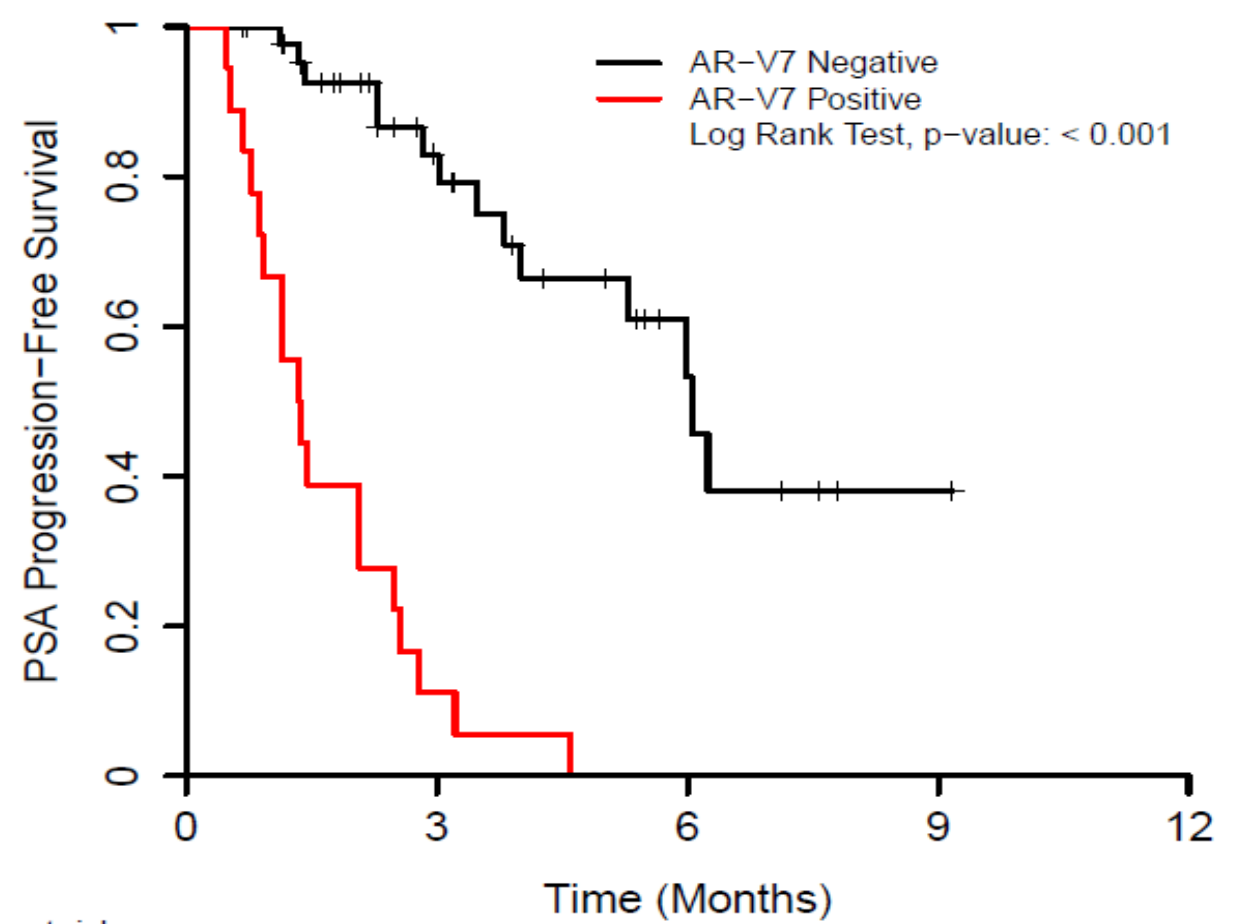

Number at risk

AR-V7 Negative: 44

AR-V7 Positive: 18

22

7

1

0

2

0

0

0 


\section{S4 C}

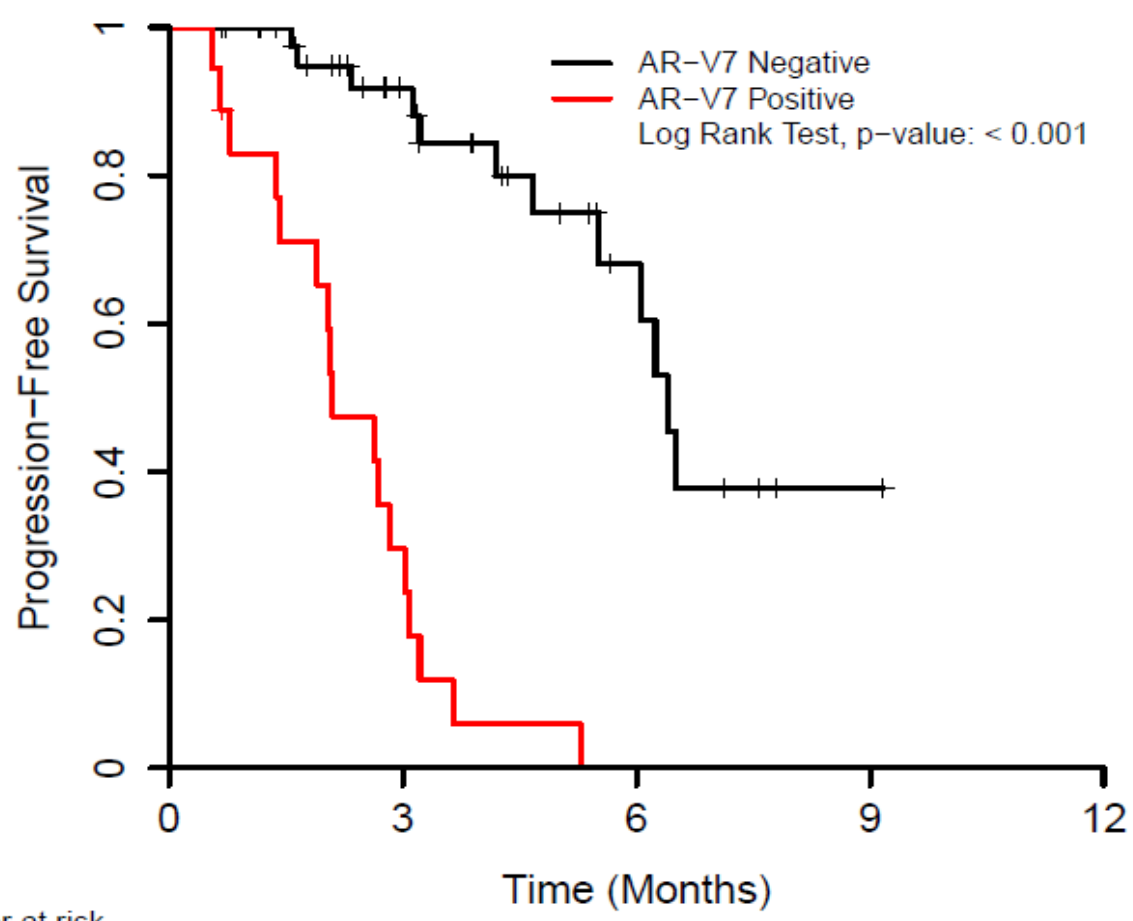

Number at risk

$\begin{array}{lcccc}\text { AR-V7 Negative: } 44 & 25 & 9 & 1 & 0 \\ \text { AR-V7 Positive: } & 18 & 5 & 0 & 0\end{array}$

S4 D

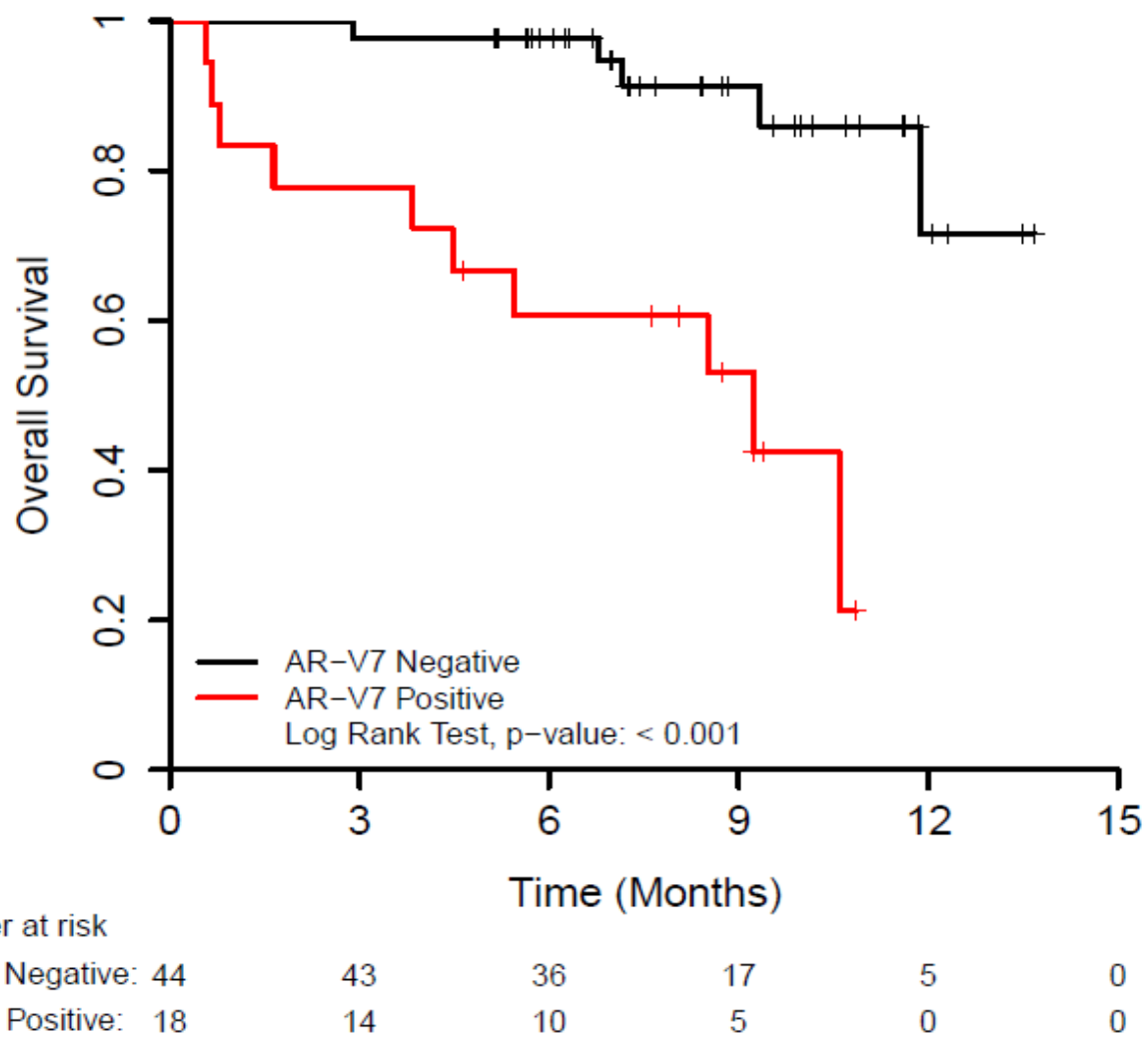


Figure S4. Combined analysis of patient outcome by AR-V7 status.

(A) Waterfall plot showing best PSA responses according to CTC AR-V7 status for all 62 patients. The 'asterisk' marks (*) indicate clipped bars. The dotted line shows the threshold for defining a PSA response. Men who had previously received abiraterone and enzalutamide (in the enzalutamide and abiraterone cohorts, respectively) are denoted with 'dagger' marks $\left({ }^{\dagger}\right)$. The overall proportion of patients who achieved a PSA response to either therapy was 44\% (27/62 men; 95\%CI, 31-57\%). PSA response rates were $0 \%(0 / 18$ men; 95\%CI, 0-19\%) in AR-V7-positive patients and 61\% (27/44 men; 95\%CI, 45$76 \%)$ in AR-V7-negative patients $(P<0.001)$. Considered alternatively, among patients achieving a PSA response, $0 \%(0 / 27$ men; 95\%CI, 0-13\%) were AR-V7-positive; while in patients not achieving a PSA response, 51\% (18/35 men; 95\%CI, 34-69\%) were AR-V7-positive. In linear regression modeling, ARV7 status remained predictive for PSA response after adjusting for AR-FL expression levels $(P<0.001)$. (B) Kaplan-Meier curves showing PSA-progression-free-survival [PSA-PFS] stratified by CTC ARV7 status in all 62 patients. Median PSA-PFS was 1.4 months $(95 \% \mathrm{CI}, 0.9-2.6)$ and 6.1 months (95\%CI, 5.3-not reached) in AR-V7-positive and AR-V7-negative patients, respectively (HR 10.5, 95\%CI 4.7-23.6, log-rank $P<0.001)$. In multivariable Cox regression analysis stratified by treatment type, AR-V7 detection remained independently predictive of PSA-PFS (HR 8.2, 95\%CI 2.7-24.9, P<0.001). Presence of visceral metastases and more prior hormonal therapies were also predictive of PSA-PFS; while AR-FL level, prior use of enzalutamide/abiraterone, and baseline PSA level were not predictive. (C) Kaplan-Meier curves showing clinical/radiographic-progression-free-survival [PFS] stratified by CTC AR-V7 status in all 62 patients. Median PFS was 2.1 months (95\%CI, 1.9-3.1) and 6.4 months (95\%CI, 6.1-not reached) in AR-V7-positive and AR-V7-negative patients, respectively (HR 12.7, 95\% CI 5.1-31.9, log-rank $P<0.001)$. In multivariable Cox regression analysis stratified by treatment type, AR-V7 detection remained independently predictive of PFS (HR 4.9, 95\%CI 1.7-13.8, $P=0.003$ ). AR-FL levels, more prior hormonal therapies and prior use of enzalutamide/abiraterone were also predictive of PFS; while baseline PSA level, and presence of visceral metastases were not predictive. (D) Kaplan-Meier curves showing overall survival [OS] stratified by CTC AR-V7 status in all 62 patients. Median OS was 9.2 months $(95 \% \mathrm{CI}, 4.5$-not reached) and $>11.9$ months $(95 \% \mathrm{CI}, 11.9-$ not reached) in AR-V7-positive and AR-V7-negative patients, respectively (HR 8.3, 95\%CI 2.5-27.4, $\log$ rank $P<0.001)$. In multivariable Cox regression analysis stratified by treatment type, AR-V7 detection remained independently predictive of $\mathrm{OS}$ ( $\mathrm{HR} 5.0,95 \% \mathrm{CI} 1.3-19.8, P=0.021$ ). Prior use of enzalutamide/abiraterone was also predictive of OS, while AR-FL level was not predictive. 
S5 A

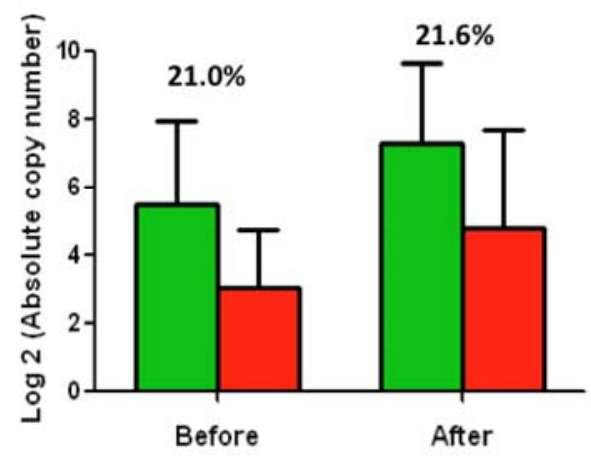

AR-V7 positive at Baseline

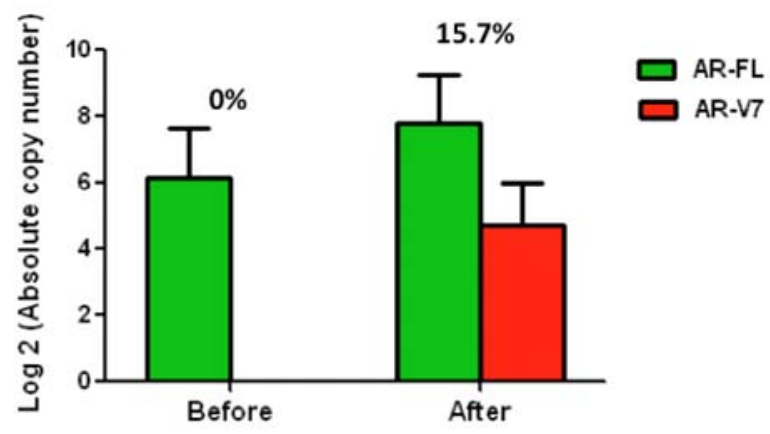

AR-V7 negative at baseline

S5 B

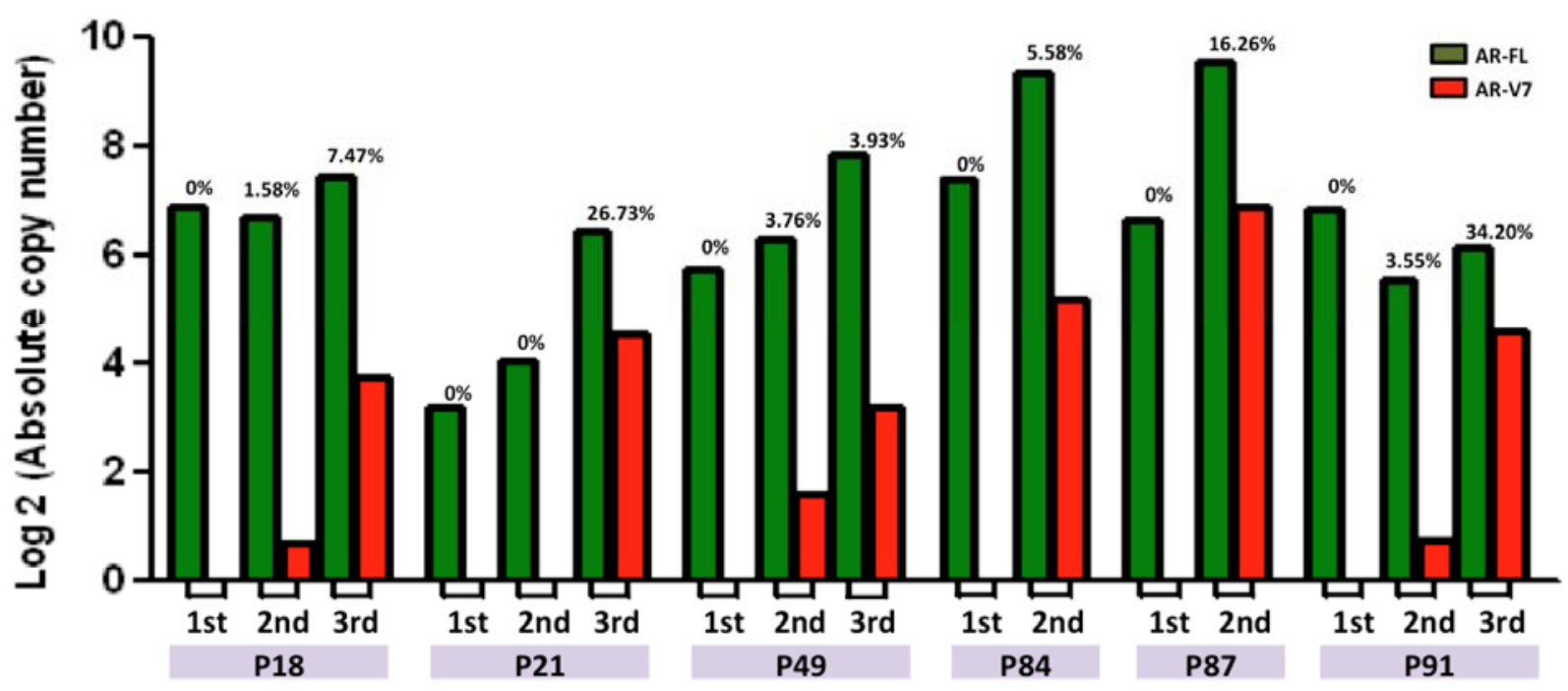


Figure S5. Changes in AR-V7 and AR-FL transcript copy numbers detected in CTCs before and after treatment with enzalutamide and abiraterone.

(A) Alterations in AR-FL and AR-V7 transcript copy numbers before and after enzalutamide/abiraterone treatment in patients with baseline detectable AR-V7 ( $\mathrm{n}=16$, with paired samples available) (left panel) and in patients who converted from initially undetectable to later detectable AR-V7 ( $\mathrm{n}=6)$ (right panel). Higher copy numbers for both AR-FL and AR-V7 were detected in CTC samples collected after treatment (at the time of resistance to therapy) compared to baseline (pretreatment) samples. Note that the AR-V7/AR-FL ratio is similar between samples collected before and after treatment in patients with baseline detectable AR-V7 ( 21\%), and that an average AR-V7/AR-FL ratio of $15.7 \%$ was detected in patients who converted from initially undetectable to later detectable AR-V7. In patients who converted from initially undetectable to later detectable AR-V7, copy number values for AR-V7 were generated from the last follow-up CTC samples (see B, below).

(B) AR transcript copy numbers detected in the 6 patients whose AR-V7 status was negative at baseline but converted to positive during treatment. Absolute transcript copy numbers for AR-FL and AR-V7 are shown for each of the 6 patients before, during, and after treatment with enzalutamide or abiraterone (1st: before treatment; 2nd: during treatment; 3rd: at the time of progression). The percentage values represent the ratio of the absolute copy number of AR-V7 to AR-FL in CTCs. As shown, absolute AR-V7 levels (and AR-V7/AR-FL ratios) increased with time in all 6 cases. Patients P18, P21, P49 and P87 were treated with enzalutamide. Patients P84 and P91 were treated with abiraterone. 
AR-FL AR-V7

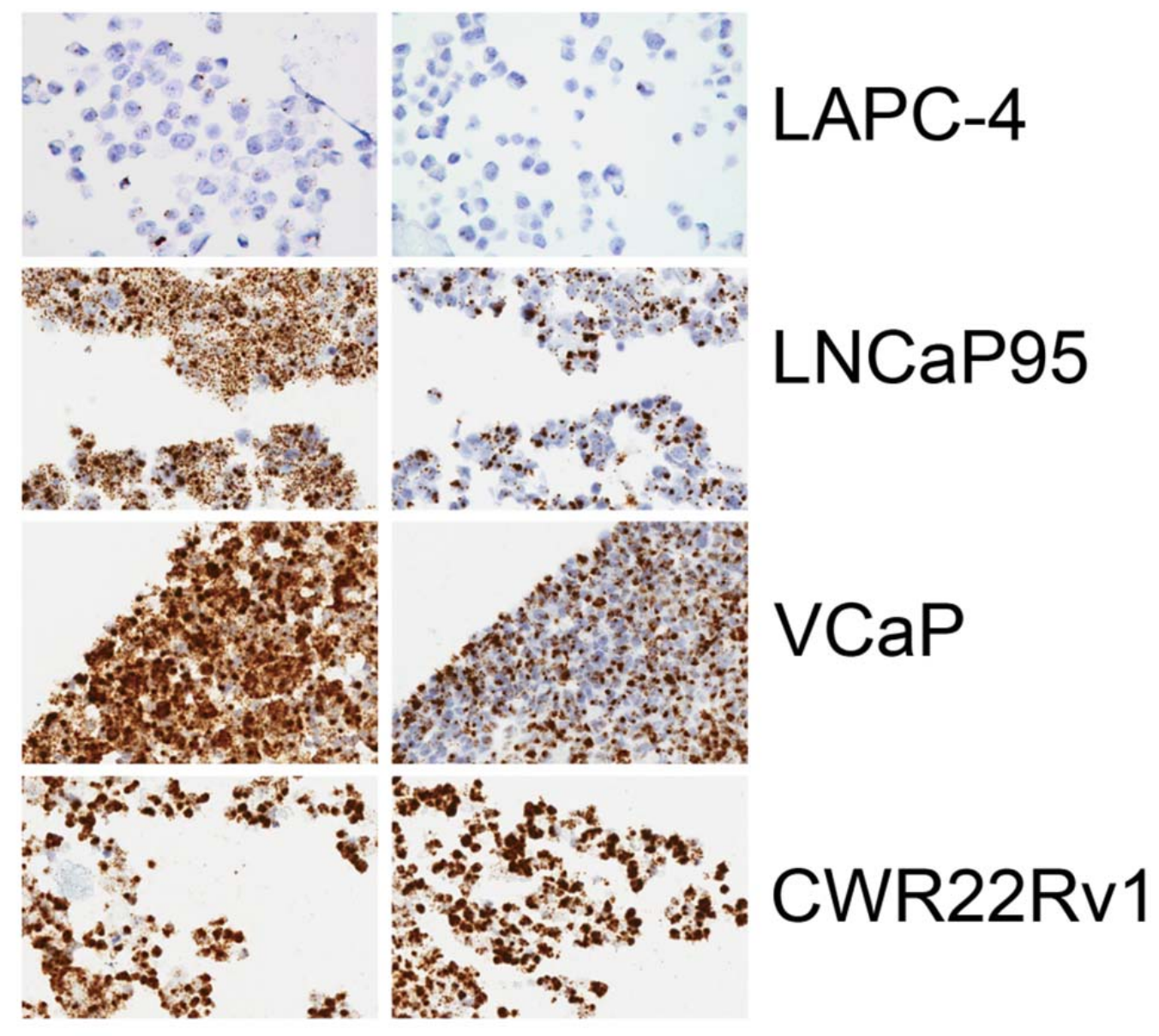

Figure S6. Detection of AR-FL and AR-V7 using RNA-ISH in cell lines with known expression of AR-FL and AR-V7.

Three of the prostate cancer cell lines shown (LNCaP95, VCaP and CWR22Rv1) express AR-FL as well as AR-V7, while the LAPC-4 line is positive only for AR-FL but negative for AR-V7, as visualized using RNA-ISH analysis. These prostate cancer cell lines served as positive and negative controls for AR-V7 detection by RNA-ISH in the patient-derived metastatic prostate cancer tissue samples shown in Fig. 4 of the main manuscript. 

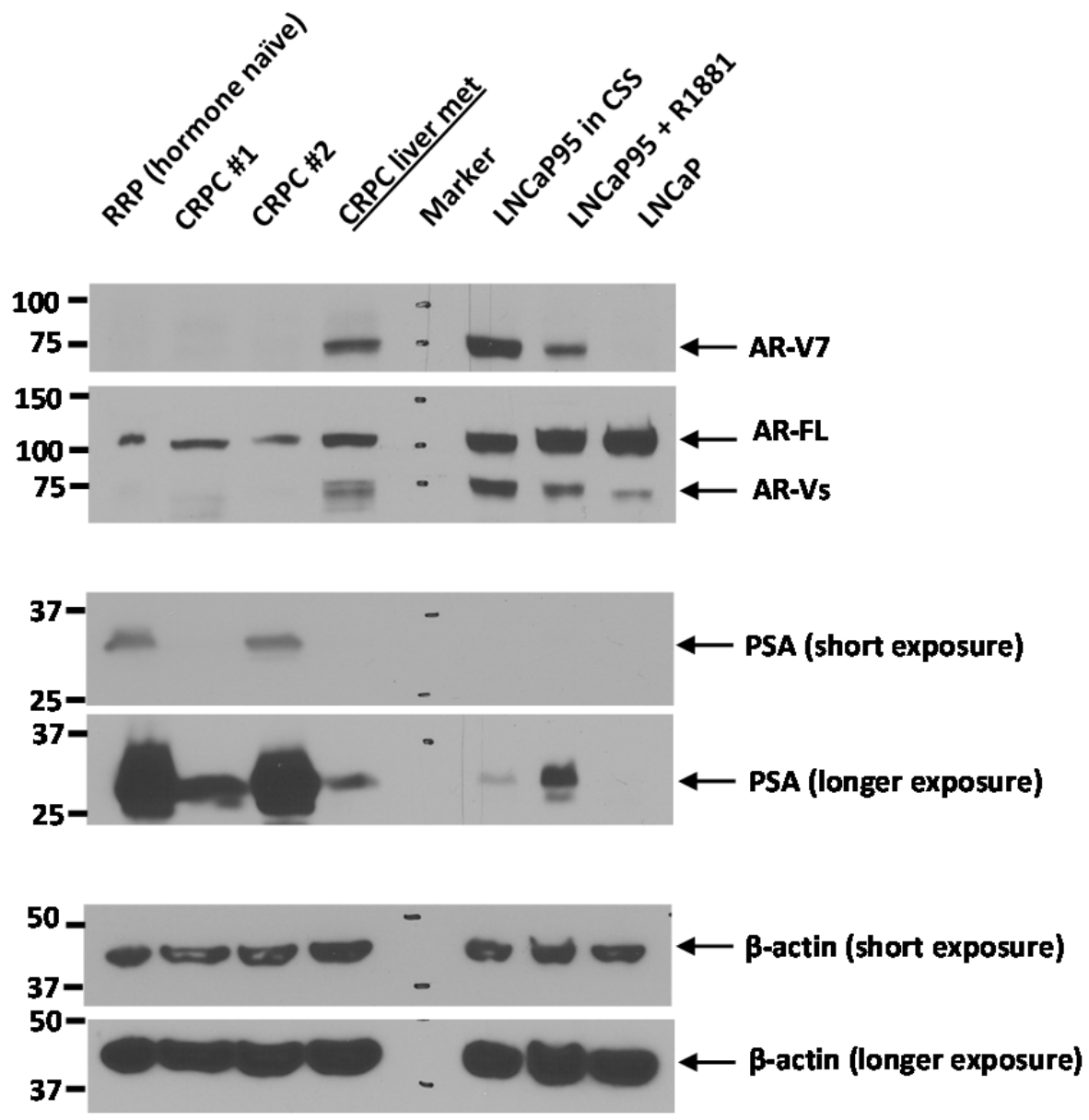

Figure S7. Detection of AR-V7 at the protein level using Western blot analysis in patients with detectable AR-V7 transcript in CTCs.

Detection of AR-V7 protein expression in a representative tissue sample, in this case from a liver metastasis from an AR-V7-positive patient (underlined label). Whole protein extractions were prepared from cryosections using RIPA buffer with protease inhibitors and phosphatase inhibitors. $40 \mu \mathrm{g}$ of protein from each sample was separated on a 10\% SDS-PAGE precast gel and blotted with anti-AR-V7, anti-AR (N20) (for detection of both AR-FL and AR-Vs), anti-PSA, and anti- $\beta$-actin antibodies. The LNCaP cell line served as the negative control for AR-V7; the LNCaP95 cell line (in the presence or absence of synthetic androgen, R1881) served as the positive control for AR-V7. Also shown for comparison are samples from a hormone-naïve radical prostatectomy specimen (RRP), and two metastatic tissue samples from AR-V7-negative patients (CRPC \#1 and CRPC \#2). Molecular weight marks are indicated to the left of the blots. 


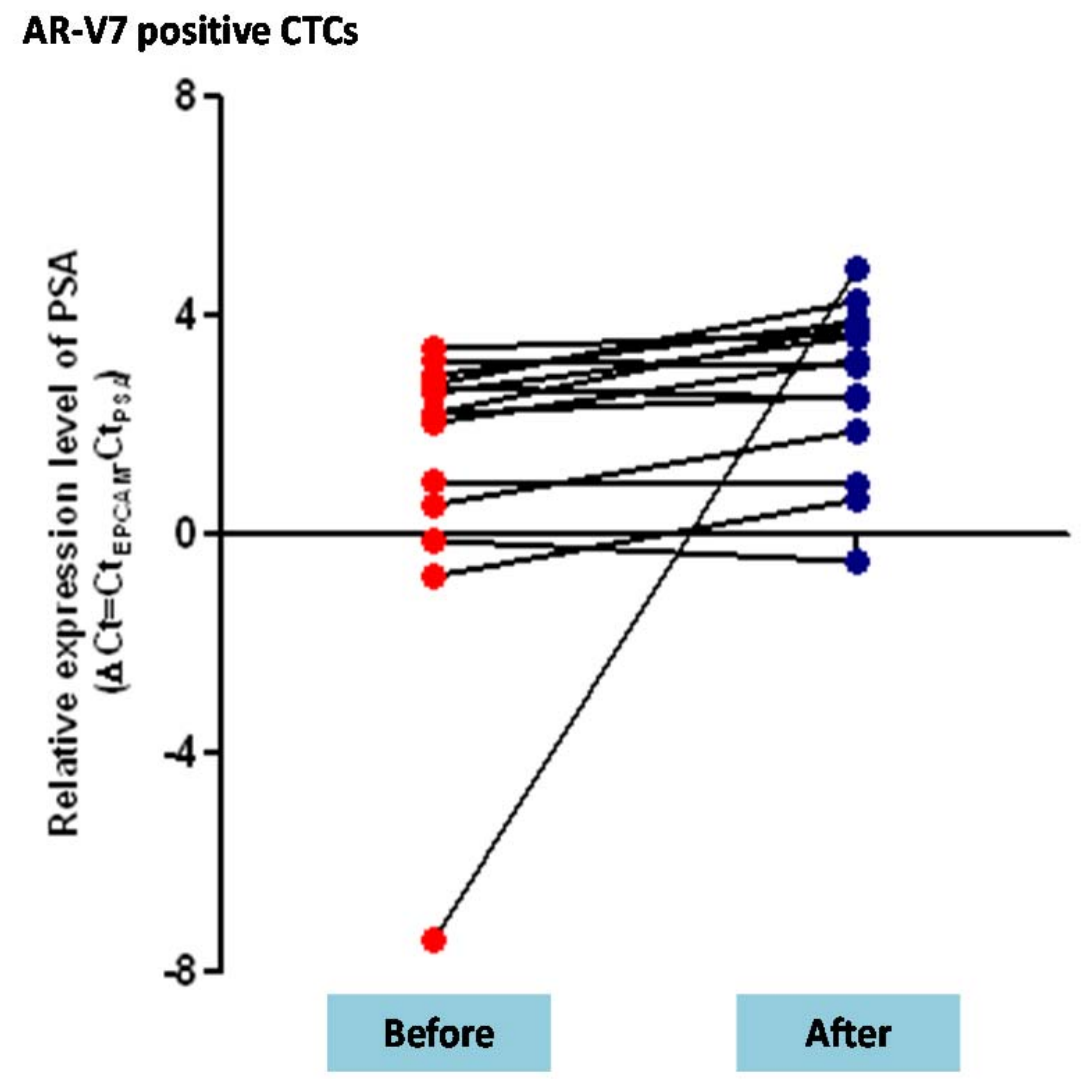

Figure S8. Changes in expression levels of the PSA transcript before and after therapy with enzalutamide or abiraterone in men with baseline detectable AR-V7.

PSA expression changes in CTC samples from AR-V7-positive patients before and after treatment with enzalutamide/abiraterone ( $\mathrm{n}=14)$, as assessed by qRT-PCR. Results are shown as the difference in $\mathrm{Ct}$ value between EPCAM and PSA expression $\left(\mathrm{Ct}_{\text {EPCAM }}-\mathrm{Ct}_{\text {PSA }}\right)$. As depicted, PSA expression was generally increased during treatment with enzalutamide/abiraterone in AR-V7-positive patients, suggesting that canonical AR signaling (as indicated by levels of PSA mRNA normalized to those of EPCAM) was not inhibited by enzalutamide/abiraterone in the presence of AR-V7. 


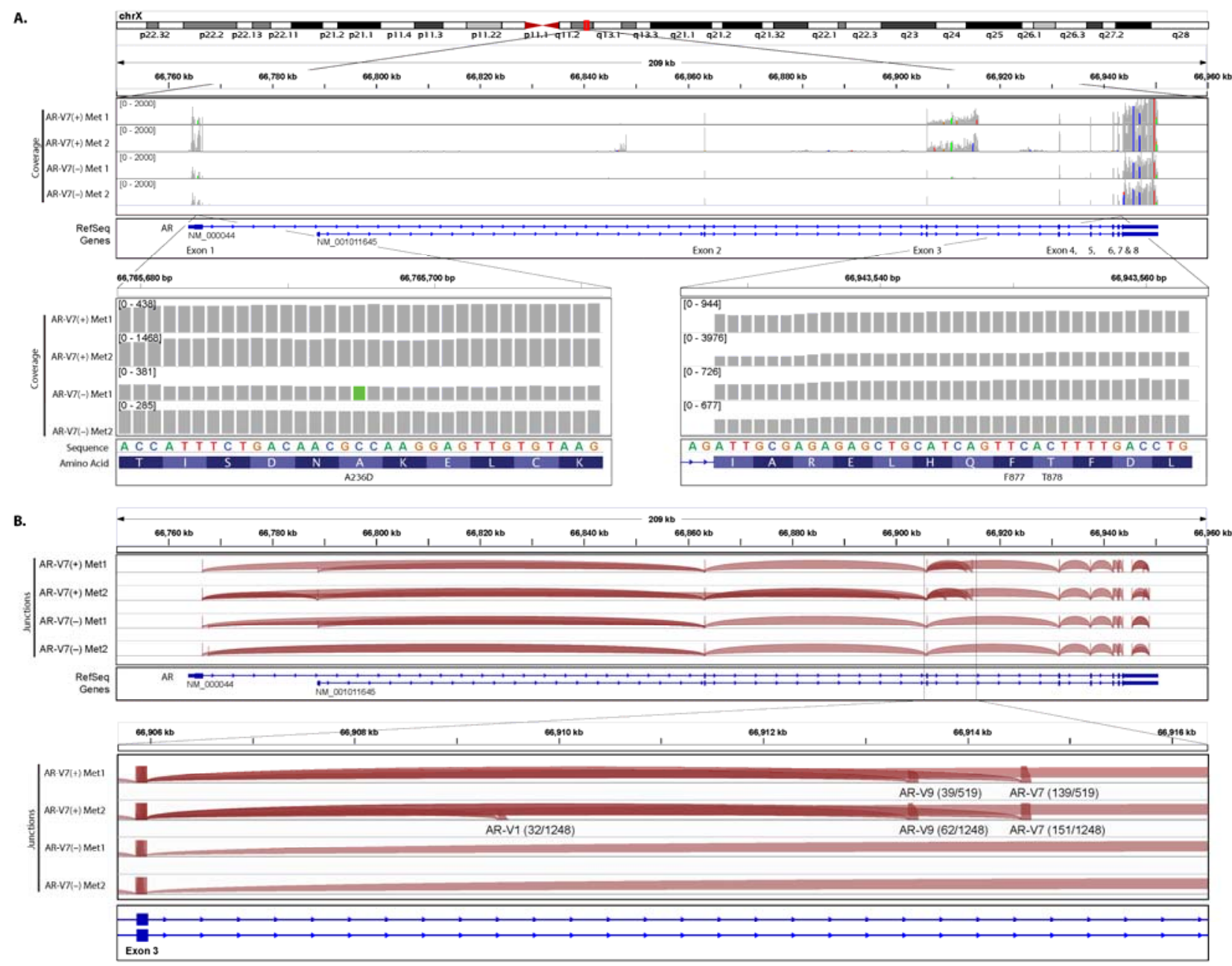

Figure S9. RNA-Seq analysis of the AR transcript in two AR-V7 (+) and two AR-V7 (-) patients.

(A) Read coverage along the AR gene, with the enlarged view showing a novel AR mutation (A236D) in exon 1 (of unknown significance) detected in an AR-V7-negative tumor, but a lack of known AR ligandbinding domain (LBD) mutations F876L and T877A previously implicated in castration resistance and enzalutamide resistance (note: due to Refseq sequence changes, the numbering of amino acid positions have increased by one). A236D is the only AR mutation detected in these four samples. (B) AR RNA splice junction tracks depicting sequence reads connecting canonical and cryptic AR exons (junctions supported by a read depth of at least 20 are shown in the figure). The enlarged region spanning exon 3 and intron 3 shows positively identified AR-V7 variants (along with AR-V1 and AR-V9) in the tissue samples from the two AR-V7-positive patients. Numbers in parentheses indicate the number of variantspecific reads over the number of AR-FL-specific reads. The AR-V7/AR-FL ratios were $26.8 \%$ and $12.1 \%$, for AR-V7(+) Met1 and AR-V7(+) Met2, respectively. 
Positive enrichment in prostate related gene sets

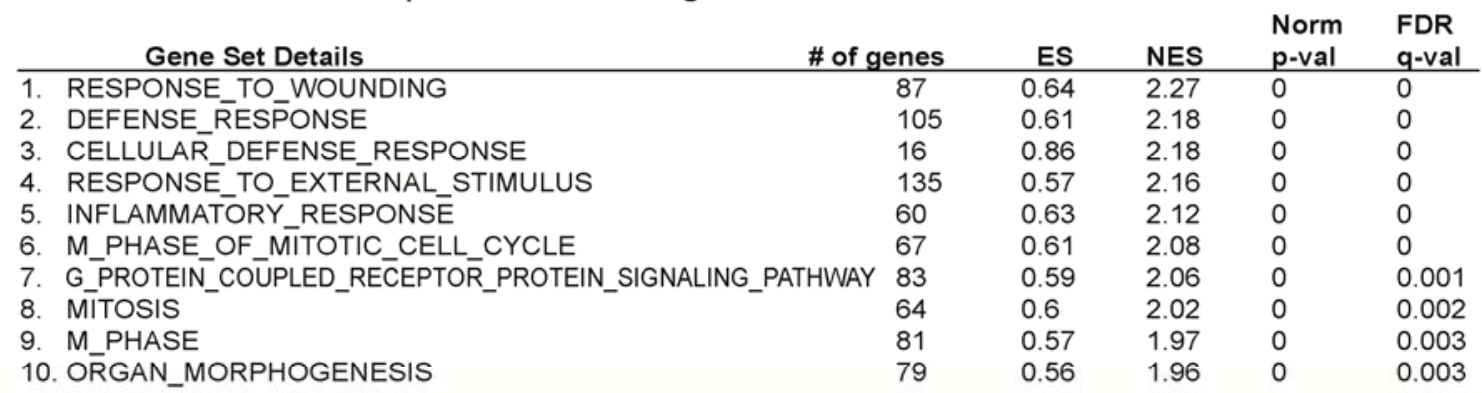
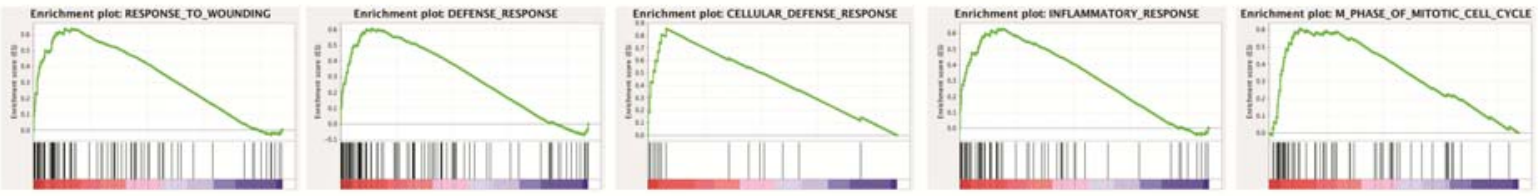

Negative enrichment in prostate related gene sets

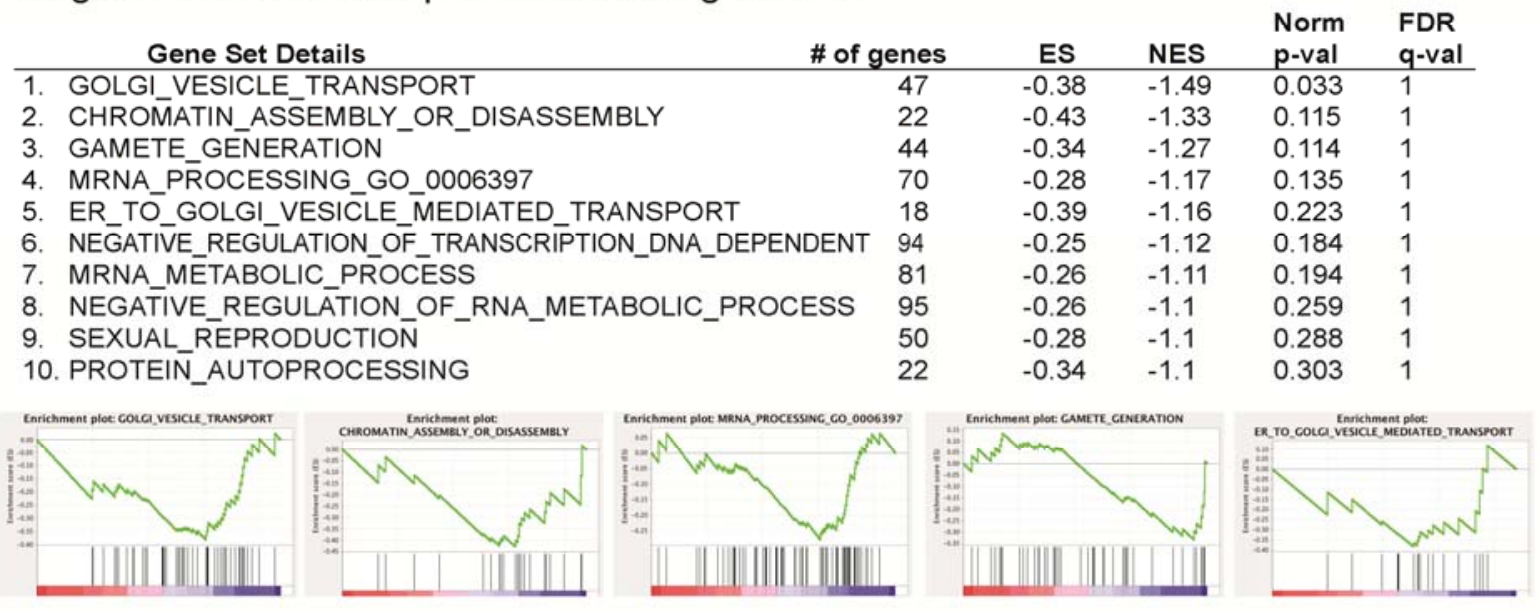

Figure S10. Gene set enrichment analysis of metastatic tumors from AR-V7-positive and AR-V7negative patients.

Top ranked 'biological processes' enriched in genes differentially expressed between AR-V7-positive and AR-V7-negative metastatic prostate cancer tissues are shown. Genes are pre-ranked based on fold expression changes. Consistent with the 'AR-V7 up' and 'AR-FL up' gene signatures reported in our previous study, ${ }^{4}$ cell cycle genes previously shown to be driven by AR-V7 (i.e., 'AR-V7 up') are enriched for increased expression in AR-V7-positive samples, and genes involved in Golgi activities, previously linked to AR-FL activity (i.e., 'AR-FL up'), are downregulated in AR-V7-positive samples.

[ES: enrichment score. NES: normalized enrichment score]. 
Table S1 A. Baseline characteristics of the 31 patients treated with enzalutamide.

\begin{tabular}{|c|c|c|c|c|}
\hline Baseline Characteristic & $\begin{array}{l}\text { All Patients } \\
\qquad(\mathrm{N}=\mathbf{3 1})\end{array}$ & $\begin{array}{l}\text { AR-V7 Negative } \\
\qquad(\mathrm{N}=19)\end{array}$ & $\begin{array}{l}\text { AR-V7 Positive } \\
\qquad(\mathrm{N}=12)\end{array}$ & P-value* \\
\hline $\begin{array}{l}\text { Age (years) } \\
\text { median (range) }\end{array}$ & $70(56-84)$ & $72(60-84)$ & $69(56-82)$ & 0.223 \\
\hline $\begin{array}{l}\text { Race, } \mathbf{N}(\%) \\
\text { white } \\
\text { non-white }\end{array}$ & $\begin{array}{c}26(83.9 \%) \\
5(16.1 \%) \\
\end{array}$ & $\begin{array}{c}16(84.2 \%) \\
3(15.8 \%)\end{array}$ & $\begin{array}{c}10(83.3 \%) \\
2(16.7 \%) \\
\end{array}$ & 0.999 \\
\hline $\begin{array}{l}\text { Time since diagnosis (years) } \\
\text { median (range) }\end{array}$ & $5(1-21)$ & $5(1-21)$ & $7(1-18)$ & 0.760 \\
\hline $\begin{array}{l}\text { Tumor stage at diagnosis, } \mathbf{N}(\%) \\
\text { T1/T2 } \\
\text { T3/T4 }\end{array}$ & $\begin{array}{l}17(54.8 \%) \\
14(45.2 \%) \\
\end{array}$ & $\begin{array}{l}10(52.6 \%) \\
9(47.4 \%) \\
\end{array}$ & $\begin{array}{l}7(58.3 \%) \\
5(41.7 \%) \\
\end{array}$ & 0.999 \\
\hline $\begin{array}{l}\text { Gleason sum at diagnosis, } \mathbf{N}(\%) \\
\leq 7 \\
\geq 8\end{array}$ & $\begin{array}{l}12(40.0 \%) \\
18(60.0 \%)\end{array}$ & $\begin{array}{c}9(47.4 \%) \\
10(52.6 \%)\end{array}$ & $\begin{array}{l}3(27.3 \%) \\
8(72.7 \%)\end{array}$ & 0.442 \\
\hline $\begin{array}{l}\text { Type of local treatment, } \mathbf{N}(\%) \\
\text { surgery } \\
\text { radiation } \\
\text { none } \\
\end{array}$ & $\begin{array}{c}13(41.9 \%) \\
7(22.6 \%) \\
11(35.5 \%) \\
\end{array}$ & $\begin{array}{l}8(42.1 \%) \\
6(31.6 \%) \\
5(26.3 \%) \\
\end{array}$ & $\begin{array}{c}5(41.7 \%) \\
1(8.3 \%) \\
6(50.0 \%) \\
\end{array}$ & 0.262 \\
\hline $\begin{array}{l}\text { Number of prior hormonal therapies } \\
\text { mean (range) }\end{array}$ & $3.3(2-5)$ & $3.2(2-5)$ & $3.4(3-5)$ & 0.317 \\
\hline $\begin{array}{l}\text { Prior use of abiraterone, } \mathbf{N}(\%) \\
\text { yes } \\
\text { no }\end{array}$ & $\begin{array}{l}20(64.5 \%) \\
11(35.5 \%)\end{array}$ & $\begin{array}{c}9(47.4 \%) \\
10(52.6 \%)\end{array}$ & $\begin{array}{c}11(91.7 \%) \\
1(8.3 \%)\end{array}$ & 0.020 \\
\hline $\begin{array}{l}\text { Prior use of docetaxel, } \mathbf{N}(\%) \\
\text { yes } \\
\text { no }\end{array}$ & $\begin{array}{l}20(64.5 \%) \\
11(35.5 \%)\end{array}$ & $\begin{array}{c}10(52.6 \%) \\
9(47.4 \%)\end{array}$ & $\begin{array}{c}10(83.3 \%) \\
2(16.7 \%)\end{array}$ & 0.128 \\
\hline $\begin{array}{l}\text { Presence of bone metastases, } \mathbf{N}(\%) \\
\text { yes } \\
\text { no }\end{array}$ & $\begin{array}{c}28(90.3 \%) \\
3(9.7 \%) \\
\end{array}$ & $\begin{array}{l}17(89.5 \%) \\
2(10.5 \%) \\
\end{array}$ & $\begin{array}{c}11(91.7 \%) \\
1(8.3 \%) \\
\end{array}$ & 0.999 \\
\hline $\begin{array}{l}\text { Number of bone metastases, } \mathbf{N}(\%) \\
\leq 5 \\
\geq 6\end{array}$ & $\begin{array}{l}20(64.5 \%) \\
11(35.5 \%)\end{array}$ & $\begin{array}{c}15(78.9 \%) \\
4(21.1 \%)\end{array}$ & $\begin{array}{l}5(41.7 \%) \\
7(58.3 \%)\end{array}$ & 0.056 \\
\hline $\begin{array}{l}\text { Presence of visceral metastases, } \mathbf{N}(\%) \\
\text { yes } \\
\text { no }\end{array}$ & $\begin{array}{l}10(32.3 \%) \\
21(67.7 \%)\end{array}$ & $\begin{array}{c}3(15.8 \%) \\
16(84.2 \%)\end{array}$ & $\begin{array}{l}7(58.3 \%) \\
5(41.7 \%)\end{array}$ & 0.021 \\
\hline $\begin{array}{l}\text { ECOG performance status score, } \mathbf{N}(\%) \\
0 \\
1 \text { or } 2\end{array}$ & $\begin{array}{l}22(71.0 \%) \\
9(29.0 \%)\end{array}$ & $\begin{array}{c}16(84.2 \%) \\
3(15.8 \%)\end{array}$ & $\begin{array}{l}6(50.0 \%) \\
6(50.0 \%)\end{array}$ & 0.056 \\
\hline $\begin{array}{l}\text { Baseline PSA (ng/mL) } \\
\text { median (range) }\end{array}$ & $\begin{array}{c}44.3 \\
(4.3-3204.2)\end{array}$ & $\begin{array}{c}29.8 \\
(4.3-452.0)\end{array}$ & $\begin{array}{c}144.3 \\
(14.5-3204.2)\end{array}$ & 0.047 \\
\hline $\begin{array}{l}\text { Baseline alkaline phosphatase (U/L) } \\
\text { median (range) }\end{array}$ & $108(58-872)$ & $91(58-872)$ & $110(82-744)$ & 0.282 \\
\hline $\begin{array}{l}\text { Baseline AR-FL level (copy number) } \\
\text { median (range) }\end{array}$ & $10(0-734)$ & $4(0-121)$ & $26(3-734)$ & 0.003 \\
\hline
\end{tabular}

* P-value is based on Fisher's Exact test and Wilcoxon Mann-Whitney test for categorical and continuous variables, respectively. 
Table S1 B. Baseline characteristics of the 31 patients treated with abiraterone.

\begin{tabular}{|c|c|c|c|c|}
\hline Baseline Characteristic & $\begin{array}{l}\text { All Patients } \\
\qquad(\mathrm{N}=\mathbf{3 1})\end{array}$ & $\begin{array}{l}\text { AR-V7 Negative } \\
\qquad(\mathrm{N}=\mathbf{2 5})\end{array}$ & $\begin{array}{l}\text { AR-V7 Positive } \\
\quad(\mathrm{N}=6)\end{array}$ & P-value* \\
\hline $\begin{array}{l}\text { Age (years) } \\
\text { median (range) }\end{array}$ & $69(48-79)$ & $69(48-79)$ & $69(58-79)$ & 0.565 \\
\hline $\begin{array}{l}\text { Race, } \mathbf{N}(\%) \\
\text { white } \\
\text { non-white }\end{array}$ & $\begin{array}{c}25(80.6 \%) \\
6(19.4 \%)\end{array}$ & $\begin{array}{c}20(80.0 \%) \\
5(20.0 \%)\end{array}$ & $\begin{array}{l}5(83.3 \%) \\
1(16.7 \%)\end{array}$ & 0.999 \\
\hline $\begin{array}{l}\text { Time since diagnosis (years) } \\
\text { median (range) }\end{array}$ & $5(1-21)$ & $5(1-13)$ & $4(1-21)$ & 0.705 \\
\hline $\begin{array}{l}\text { Tumor stage at diagnosis, } \mathbf{N}(\%) \\
\text { T1/T2 } \\
\text { T3/T4 }\end{array}$ & $\begin{array}{l}12(38.7 \%) \\
19(61.3 \%)\end{array}$ & $\begin{array}{l}10(40.0 \%) \\
15(60.0 \%)\end{array}$ & $\begin{array}{l}2(33.3 \%) \\
4(66.7 \%) \\
\end{array}$ & 0.999 \\
\hline $\begin{array}{l}\text { Gleason sum at diagnosis, } \mathbf{N}(\%) \\
\leq 7 \\
\geq 8\end{array}$ & $\begin{array}{c}8(26.7 \%) \\
22(73.3 \%)\end{array}$ & $\begin{array}{c}6(24.0 \%) \\
19(76.0 \%)\end{array}$ & $\begin{array}{l}2(40.0 \%) \\
3(60.0 \%) \\
\end{array}$ & 0.589 \\
\hline $\begin{array}{l}\text { Type of local treatment, } \mathbf{N}(\%) \\
\text { surgery } \\
\text { radiation } \\
\text { none }\end{array}$ & $\begin{array}{c}14(45.2 \%) \\
10(32.3 \%) \\
7(22.6 \%) \\
\end{array}$ & $\begin{array}{l}10(40.0 \%) \\
9(36.0 \%) \\
6(24.0 \%) \\
\end{array}$ & $\begin{array}{l}4(66.6 \%) \\
1(16.7 \%) \\
1(16.7 \%) \\
\end{array}$ & 0.520 \\
\hline $\begin{array}{l}\text { Number of prior hormonal therapies } \\
\text { mean (range) }\end{array}$ & $2.5(2-6)$ & $2.2(2-4)$ & $3.7(2-6)$ & 0.020 \\
\hline $\begin{array}{l}\text { Prior use of enzalutamide, } \mathbf{N}(\%) \\
\text { yes } \\
\text { no }\end{array}$ & $\begin{array}{c}4(12.9 \%) \\
27(87.1 \%)\end{array}$ & $\begin{array}{c}2(8.0 \%) \\
23(92.0 \%)\end{array}$ & $\begin{array}{l}2(33.3 \%) \\
4(66.7 \%) \\
\end{array}$ & 0.159 \\
\hline $\begin{array}{l}\text { Prior use of docetaxel, } \mathbf{N}(\%) \\
\text { yes } \\
\text { no } \\
\end{array}$ & $\begin{array}{c}5(16.1 \%) \\
26(83.9 \%)\end{array}$ & $\begin{array}{c}4(16.0 \%) \\
21(84.0 \%)\end{array}$ & $\begin{array}{l}1(16.7 \%) \\
5(83.3 \%)\end{array}$ & 0.999 \\
\hline $\begin{array}{l}\text { Presence of bone metastases, } \mathbf{N}(\%) \\
\text { yes } \\
\text { no }\end{array}$ & $\begin{array}{l}24(77.4 \%) \\
7(22.6 \%)\end{array}$ & $\begin{array}{c}19(76.0 \%) \\
6(24.0 \%)\end{array}$ & $\begin{array}{l}5(83.3 \%) \\
1(16.7 \%)\end{array}$ & 0.999 \\
\hline $\begin{array}{l}\text { Number of bone metastases, } \mathbf{N}(\%) \\
\quad \leq 5 \\
\geq 6\end{array}$ & $\begin{array}{l}17(54.8 \%) \\
14(45.2 \%) \\
\end{array}$ & $\begin{array}{l}15(60.0 \%) \\
10(40.4 \%)\end{array}$ & $\begin{array}{l}2(33.3 \%) \\
4(66.7 \%) \\
\end{array}$ & 0.370 \\
\hline $\begin{array}{l}\text { Presence of visceral metastases, } \mathbf{N}(\%) \\
\text { yes } \\
\text { no }\end{array}$ & $\begin{array}{l}8(25.8 \%) \\
23(74.2 \%)\end{array}$ & $\begin{array}{c}8(32.0 \%) \\
17(68.0 \%)\end{array}$ & $\begin{array}{c}0(0 \%) \\
6(100 \%)\end{array}$ & 0.298 \\
\hline $\begin{array}{l}\text { ECOG performance status score, } \mathbf{N}(\%) \\
0 \\
1 \text { or } 2\end{array}$ & $\begin{array}{c}25(80.6 \%) \\
6(19.4 \%) \\
\end{array}$ & $\begin{array}{c}22(88.0 \%) \\
3(12.0 \%)\end{array}$ & $\begin{array}{l}3(50.0 \%) \\
3(50.0 \%) \\
\end{array}$ & 0.069 \\
\hline $\begin{array}{l}\text { Baseline PSA (ng/mL) } \\
\text { median (range) }\end{array}$ & $\begin{array}{c}37.8 \\
(2.2-2045.0) \\
\end{array}$ & $\begin{array}{c}31.4 \\
(2.2-262.2) \\
\end{array}$ & $\begin{array}{c}86.9 \\
(19.4-2045.0)\end{array}$ & 0.084 \\
\hline $\begin{array}{l}\text { Baseline alkaline phosphatase (U/L) } \\
\text { median (range) }\end{array}$ & $118(59-1348)$ & $109(59-524)$ & $263(71-1348)$ & 0.063 \\
\hline $\begin{array}{l}\text { Baseline AR-FL level (copy number) } \\
\text { median (range) }\end{array}$ & $3(0-609)$ & $1(0-173)$ & $216(8-609)$ & 0.002 \\
\hline
\end{tabular}

${ }^{*}$ P-value is based on Fisher's Exact test and Wilcoxon Mann-Whitney test for categorical and continuous variables, respectively. 
Table S2. Clinical outcomes (PSA responses, PSA-PFS and PFS) reported separately according to prior exposure to abiraterone (in the enzalutamide cohort) and prior exposure to enzalutamide (in the abiraterone cohort).

A. Enzalutamide cohort: Clinical outcomes according to prior exposure (or not) to abiraterone

\begin{tabular}{|l|c|c|c|c|c|c|}
\hline \multirow{2}{*}{ Outcome } & \multicolumn{3}{|c|}{$\begin{array}{c}\text { No previous abiraterone } \\
(\mathrm{n}=11)\end{array}$} & \multicolumn{3}{c|}{$\begin{array}{c}\text { Previous abiraterone } \\
(\mathrm{n}=20)\end{array}$} \\
\cline { 2 - 7 } & $\begin{array}{c}\text { AR-V7 [+] } \\
(\mathrm{n}=1)\end{array}$ & $\begin{array}{c}\text { AR-V7 }[-] \\
(\mathrm{n}=10)\end{array}$ & $P$ value & $\begin{array}{c}\text { AR-V7 [+] } \\
(\mathrm{n}=11)\end{array}$ & $\begin{array}{c}\text { AR-V7 [-] } \\
(\mathrm{n}=9)\end{array}$ & $P$ value \\
\hline PSA Response & $0 \%(0 / 1)$ & $80 \%(8 / 10)$ & 0.273 & $0 \%(0 / 11)$ & $22 \%(2 / 9)$ & 0.189 \\
\hline PFA-PFS & \multicolumn{2}{|c|}{ HR (95\%CI) not estimable } & 0.005 & HR 3.34 (95\%CI, 1.14-9.80) & 0.021 \\
\hline PFS & \multicolumn{2}{|c|}{ HR (95\%CI) not estimable } & 0.005 & HR 2.93 (95\%CI, 0.96-8.90) & 0.048 \\
\hline
\end{tabular}

B. Abiraterone cohort: Clinical outcomes according to prior exposure (or not) to enzalutamide

\begin{tabular}{|l|c|c|c|c|c|c|}
\hline \multirow{2}{*}{ Outcome } & \multicolumn{3}{|c|}{$\begin{array}{c}\text { No previous enzalutamide } \\
(\mathrm{n}=27)\end{array}$} & \multicolumn{3}{c|}{$\begin{array}{c}\text { Previous enzalutamide } \\
(\mathrm{n}=4)\end{array}$} \\
\cline { 2 - 6 } & $\begin{array}{c}\text { AR-V7 [+] } \\
(\mathrm{n}=4)\end{array}$ & $\begin{array}{c}\text { AR-V7 [-] } \\
(\mathrm{n}=23)\end{array}$ & $P$ value & $\begin{array}{c}\text { AR-V7 }[+] \\
(\mathrm{n}=2)\end{array}$ & $\begin{array}{c}\text { AR-V7 }[-] \\
(\mathrm{n}=2)\end{array}$ & $P$ value \\
\hline PSA Response & $0 \%(0 / 4)$ & $74 \%(17 / 23)$ & 0.012 & $0 \%(0 / 2)$ & $0 \%(0 / 2)$ & N/A \\
\hline PFA-PFS & \multicolumn{2}{|c|}{ HR 41.0 $(95 \% \mathrm{CI}, 4.5-376.8)$} & $<0.001$ & HR $(95 \% \mathrm{CI})$ not estimable & N/A \\
\hline PFS & \multicolumn{2}{|c|}{ HR $28.2(95 \% \mathrm{CI}, 3.1-255.8)$} & $<0.001$ & HR $(95 \% \mathrm{CI})$ not estimable & N/A \\
\hline
\end{tabular}

C. Combined cohort: Clinical outcomes according to prior exposure to abiraterone/enzalutamide

\begin{tabular}{|c|c|c|c|c|c|c|}
\hline \multirow{2}{*}{ Outcome } & \multicolumn{3}{|c|}{$\begin{array}{l}\text { No prior abiraterone/enzalutamide } \\
\qquad(\mathrm{n}=38)\end{array}$} & \multicolumn{3}{|c|}{$\begin{array}{l}\text { Prior abiraterone/enzalutamide } \\
\qquad(\mathrm{n}=24)\end{array}$} \\
\hline & $\begin{array}{l}\text { AR-V7 }[+] \\
\quad(n=5)\end{array}$ & $\begin{array}{c}\text { AR-V7 [-] } \\
(\mathrm{n}=33)\end{array}$ & $P$ value & $\begin{array}{l}\text { AR-V7 }[+] \\
\quad(n=13)\end{array}$ & $\begin{array}{l}\text { AR-V7 }[-] \\
\quad(\mathrm{n}=11)\end{array}$ & $P$ value \\
\hline PSA Response & $0 \%(0 / 5)$ & $76 \% \quad(25 / 33)$ & 0.003 & $0 \%(0 / 13)$ & $18 \%(2 / 11)$ & 0.199 \\
\hline PFA-PFS & \multicolumn{2}{|c|}{ HR 55.9 (95\%CI, 6.4-488.5) } & $<0.001$ & \multicolumn{2}{|c|}{ HR 2.91 (95\%CI, 1.10-7.72) } & 0.023 \\
\hline PFS & \multicolumn{2}{|c|}{ HR 45.2 (95\%CI, 5.1-398.1) } & $<0.001$ & \multicolumn{2}{|c|}{ HR 2.65 (95\%CI, 0.97-7.25) } & 0.048 \\
\hline
\end{tabular}


Table S3. Propensity score weighted multivariable Cox models adjusted for Gleason score, baseline PSA, number of prior hormonal treatments, presence of visceral metastases, ECOG score, prior abiraterone/enzalutamide use, and AR-FL levels.

A. Propensity score weighted multivariable Cox model for PSA-PFS in enzalutamide-treated men

\begin{tabular}{|l|c|c|c|}
\hline Variable & Hazard Ratio (HR) & 95\% Confidence Interval $(95 \% \mathrm{CI})$ & $P$ value \\
\hline AR-V7 Positive & 3.40 & $(1.43-8.08)$ & 0.006 \\
\hline AR-FL Level $(\log )$ & 1.33 & $(1.03-1.72)$ & \\
\hline Prior use of Abiraterone & 2.66 & $(0.72-9.86)$ & \\
\hline
\end{tabular}

B. Propensity score weighted multivariable Cox model for PFS in enzalutamide-treated men

\begin{tabular}{|l|c|c|c|}
\hline Variable & Hazard Ratio (HR) & 95\% Confidence Interval $(95 \% \mathrm{CI})$ & $P$ value \\
\hline AR-V7 Positive & 3.38 & $(1.35-8.46)$ & 0.009 \\
\hline AR-FL Level (log) & 1.64 & $(1.14-2.35)$ & \\
\hline Prior use of Abiraterone & 1.54 & $(0.31-7.79)$ & \\
\hline
\end{tabular}

C. Propensity score weighted multivariable Cox model for PSA-PFS in abiraterone-treated men

\begin{tabular}{|l|c|c|c|}
\hline Variable & Hazard Ratio (HR) & 95\% Confidence Interval $(95 \% \mathrm{CI})$ & $P$ value \\
\hline AR-V7 Positive & 17.51 & $(3.53-87.03)$ & $<0.001$ \\
\hline AR-FL Level (log) & 1.05 & $(0.87-1.25)$ & \\
\hline Prior use of Enzalutamide & 0.61 & $(0.17-2.19)$ & \\
\hline
\end{tabular}

D. Propensity score weighted multivariable Cox model for PFS in abiraterone-treated men

\begin{tabular}{|l|c|c|c|}
\hline Variable & Hazard Ratio (HR) & 95\% Confidence Interval $(95 \% \mathrm{CI})$ & $P$ value \\
\hline AR-V7 Positive & 5.25 & $(1.09-25.21)$ & 0.038 \\
\hline AR-FL Level (log) & 1.36 & $(0.97-1.90)$ & \\
\hline Prior use of Enzalutamide & 1.72 & $(0.50-5.92)$ & \\
\hline
\end{tabular}


Table S4. Clinical outcomes (PSA responses, PSA-PFS and PFS) for the entire patient population according to their AR-V7 'conversion' rates.

Footnote: Of the 44 patients who were AR-V7-negative at baseline, 42 had at least one followup sample collected; 36 of these men (86\%) remained AR-V7-negative at follow-up (AR-V7[-] $\rightarrow$ AR-V7[-]), while 6 of these men (14\%) converted to AR-V7-positive at follow-up (AR-V7[]$\rightarrow \mathrm{AR}-\mathrm{V} 7[+])$. Of the 18 patients who were AR-V7-positive at baseline, 16 had at least one follow-up sample collected; all of these men remained AR-V7-positive at follow-up (AR-V7[+] $\rightarrow$ AR-V7[+]). The clinical outcomes of these patients are also shown.

These data should be interpreted with caution (and are hypothesis-generating only) because we have not taken into account the timing of the subsequent sample collection, and we have not performed time-dependent covariate analysis or landmark analysis to adjust for this. Therefore, the clinical outcomes in each group cannot be formally compared with each other, and are provided for descriptive purposes only.

\begin{tabular}{|l|c|c|c|}
\hline Outcome & $\begin{array}{c}\text { AR-V7[-] } \rightarrow \text { AR-V7[-] } \\
(\mathrm{n}=36)\end{array}$ & $\begin{array}{c}\text { AR-V7[-] } \rightarrow \text { AR-V7[+] } \\
(\mathrm{n}=6)\end{array}$ & $\begin{array}{c}\text { AR-V7[+] } \rightarrow \text { AR-V7[+] } \\
(\mathrm{n}=16)\end{array}$ \\
\hline \multirow{2}{*}{ PSA Response } & $\begin{array}{c}68 \% \\
(95 \% \mathrm{CI}, 52-81 \%)\end{array}$ & $\begin{array}{c}17 \% \\
(95 \% \mathrm{CI}, 4-58 \%)\end{array}$ & $(95 \% \mathrm{CI}, 0-19 \%)$ \\
\hline \multirow{2}{*}{ PFA-PFS } & $6.1 \mathrm{months}$ & $3.0 \mathrm{months}$ & $1.4 \mathrm{months}$ \\
\hline \multirow{2}{*}{ PFS } & $(95 \% \mathrm{CI}, 5.9 \mathrm{mo}-\mathrm{NA})$ & $(95 \% \mathrm{CI}, 2.3 \mathrm{mo}-\mathrm{NA})$ & $(95 \% \mathrm{CI}, 0.9-2.6 \mathrm{mo})$ \\
\hline
\end{tabular}




\section{Table S5. Expression profiles of AR-regulated genes in AR-V7-positive and AR-V7-negative metastatic tumors.}

Footnote: A total of 34 canonical AR regulated genes were identified by combined analysis of downloaded expression data reported in two published studies. ${ }^{1,11}$ The AR gene did not make the selection but was added for reference. For each of the 35 genes, the number of raw RNA-Seq reads and sequencing reads normalized by "Reads Per Kilo Gene Size Per Million of Total Reads" (RPKM= number of raw counts/(genelength/1000)/(total-reads/1,000,000) in each of the four tumor samples, as well as the log fold expression change between AR-V7-positive and AR-V7-negative tumors calculated from RPKM-normalized data, are displayed. Annexed to the RNA-Seq data are previously published expression microarray data ${ }^{4}$ characterizing AR-V7- versus AR-FL-driven transcriptional programs (expression ratios normalized to a common reference sample were downloaded from GEO accession number GSE36549). Fold expression changes in AR-V7-positive samples when compared to AR-V7-negative tumors (log FC) are significantly correlated $(P<0.001$, with a correlation coefficient of 0.68$)$ with fold expression changes induced by AR-V7 in the absence of AR-FL activation (log FC by ARV7), but not significantly correlated ( $p>0.05$, with a correlation coefficient of 0.23 ) with fold expression changes induced by AR-FL activation (log FC by ARFL).

\begin{tabular}{|c|c|c|c|c|c|c|c|c|c|c|c|c|c|c|c|c|}
\hline Gene & $\begin{array}{l}\text { Size } \\
\text { (bp) }\end{array}$ & $\begin{array}{l}\text { Raw } \\
\text { V7(-) } \\
\text { Met } 1\end{array}$ & $\begin{array}{l}\text { Raw } \\
\text { V7(-) } \\
\text { Met } 2\end{array}$ & $\begin{array}{l}\text { Raw } \\
\text { V7(+) } \\
\text { Met } 1\end{array}$ & $\begin{array}{l}\text { Raw } \\
\text { V7(+) } \\
\text { Met } 2\end{array}$ & $\begin{array}{c}\text { RPKM } \\
\text { V7(-) } \\
\text { Met } 1\end{array}$ & $\begin{array}{c}\text { RPKM } \\
\text { V7(-) } \\
\text { Met } 2\end{array}$ & $\begin{array}{c}\text { RPKM } \\
\text { V7(+) } \\
\text { Met } 1\end{array}$ & $\begin{array}{l}\text { RPKM } \\
\text { V7(+) } \\
\text { Met } 2\end{array}$ & $\begin{array}{l}\log \\
F C\end{array}$ & CSS & R1881 & $\begin{array}{c}\text { CSS } \\
+ \\
\text { ARV7 }\end{array}$ & $\begin{array}{c}\text { R1881 } \\
+ \\
\text { ARV7 }\end{array}$ & $\begin{array}{c}\log \text { FC } \\
\text { by } \\
\text { ARV7 }\end{array}$ & $\begin{array}{c}\underset{\text { by }}{\log F C} \\
\text { ARFL }\end{array}$ \\
\hline$A R$ & 4496 & 23044 & 20645 & 21722 & 62370 & 111.83 & 92.43 & 54.53 & 201.92 & -0.22 & 0.10 & -0.89 & -0.01 & -0.96 & -0.11 & -0.99 \\
\hline C1orf116 & 5502 & 3123 & 5063 & 3293 & 10168 & 12.38 & 18.52 & 6.75 & 26.90 & -0.62 & -0.90 & 1.05 & -0.90 & 0.99 & 0.01 & 1.95 \\
\hline CENPN & 5307 & 1337 & 11671 & 1799 & 907 & 5.50 & 44.27 & 3.83 & 2.49 & -3.26 & -2.67 & 0.52 & -1.92 & 0.88 & 0.75 & 3.20 \\
\hline CXCR4 & 2005 & 654 & 695 & 10593 & 7739 & 7.12 & 6.98 & 59.63 & 56.18 & 2.65 & -0.40 & 2.77 & -0.26 & 3.51 & 0.13 & 3.17 \\
\hline$D B I$ & 1260 & 11624 & 10108 & 43384 & 10800 & 201.28 & 161.47 & 388.60 & 124.76 & 0.11 & -0.50 & 3.07 & 0.33 & 3.19 & 0.82 & 3.57 \\
\hline EAF2 & 1020 & 66 & 212 & 3689 & 116 & 1.41 & 4.18 & 40.82 & 1.66 & 0.74 & 0.10 & 4.18 & 0.37 & 3.77 & 0.28 & 4.08 \\
\hline$E B P$ & 1157 & 784 & 3333 & 3322 & 2755 & 14.78 & 57.98 & 32.40 & 34.66 & -0.20 & -0.48 & 0.88 & -0.07 & 0.75 & 0.41 & 1.35 \\
\hline FASN & 8458 & 2272 & 5891 & 19983 & 46976 & 5.86 & 14.02 & 26.66 & 80.84 & 1.97 & -0.50 & 0.61 & -0.06 & 0.86 & 0.44 & 1.11 \\
\hline FKBP5 & 10628 & 3810 & 34978 & 55568 & 66987 & 7.82 & 66.24 & 59.01 & 91.74 & 1.32 & -1.28 & 3.61 & 1.26 & 4.03 & 2.54 & 4.89 \\
\hline FZD5 & 6564 & 3247 & 6014 & 3756 & 2384 & 10.79 & 18.44 & 6.46 & 5.29 & -1.98 & -1.12 & 1.65 & -0.93 & 1.80 & 0.19 & 2.77 \\
\hline
\end{tabular}




\begin{tabular}{|c|c|c|c|c|c|c|c|c|c|c|c|c|c|c|c|c|}
\hline HMGCR & 4582 & 2395 & 3169 & 3526 & 2334 & 11.40 & 13.92 & 8.68 & 7.41 & -1.25 & 0.06 & 1.54 & 0.07 & 1.27 & 0.01 & 1.49 \\
\hline HMGCS1 & 3510 & 2596 & 5207 & 12367 & 3282 & 16.14 & 29.86 & 39.76 & 13.61 & -0.38 & 0.40 & 2.15 & 0.65 & 1.79 & 0.25 & 1.75 \\
\hline HPGD & 3022 & 127 & 57 & 392 & 29067 & 0.92 & 0.38 & 1.46 & 140.00 & 3.64 & -2.52 & 3.46 & -0.05 & 4.05 & 2.47 & 5.98 \\
\hline INSIG1 & 3081 & 421 & 3684 & 3118 & 8029 & 2.98 & 24.07 & 11.42 & 37.93 & 0.90 & -0.58 & 1.55 & 0.27 & 2.00 & 0.85 & 2.13 \\
\hline$K L K 2$ & 2872 & 286904 & 327838 & 82985 & 16542 & 2179.51 & 2297.62 & 326.10 & 83.84 & -3.76 & -4.34 & 0.14 & -3.86 & 0.37 & 0.48 & 4.48 \\
\hline$K L K 3$ & 2214 & 213712 & 922556 & 121923 & 32693 & 2106.00 & 8387.23 & 621.51 & 214.93 & -3.03 & -3.75 & -0.16 & -2.95 & 0.37 & 0.80 & 3.59 \\
\hline$K L K 4$ & 1347 & 2478 & 3956 & 813 & 4579 & 40.14 & 59.11 & 6.81 & 49.48 & -1.81 & -2.68 & -0.19 & -2.59 & -0.20 & 0.08 & 2.49 \\
\hline LDLR & 5283 & 149 & 1947 & 2714 & 5261 & 0.62 & 7.42 & 5.80 & 14.49 & 1.47 & -0.82 & 1.70 & -0.23 & 1.50 & 0.60 & 2.52 \\
\hline MAF & 6878 & 425 & 778 & 4311 & 1659 & 1.35 & 2.28 & 7.07 & 3.51 & 0.59 & -1.22 & 2.98 & -1.54 & 2.81 & -0.32 & 4.20 \\
\hline MICAL1 & 3644 & 685 & 88 & 2959 & 2630 & 4.10 & 0.49 & 9.16 & 10.51 & 2.00 & 0.32 & 3.28 & 0.28 & 3.14 & -0.04 & 2.96 \\
\hline NCAPD3 & 5605 & 849 & 1024 & 2601 & 4880 & 3.30 & 3.68 & 5.24 & 12.67 & 0.63 & -0.62 & 2.50 & -0.22 & 2.55 & 0.41 & 3.12 \\
\hline NDRG1 & 3478 & 66845 & 19467 & 44162 & 124199 & 419.32 & 112.66 & 143.30 & 519.78 & 0.22 & -1.02 & 2.99 & 0.11 & 3.35 & 1.14 & 4.01 \\
\hline NKX3-1 & 3281 & 35635 & 53042 & 44160 & 43298 & 236.96 & 325.40 & 151.90 & 192.08 & -0.89 & -2.62 & 1.17 & -2.59 & 1.04 & 0.04 & 3.80 \\
\hline ORM1 & 839 & 3 & 2407 & 94992 & 21539 & 0.08 & 57.75 & 1277.81 & 373.67 & 7.90 & -0.88 & 4.10 & 6.70 & 6.47 & 7.57 & 4.97 \\
\hline PMEPA1 & 5186 & 10061 & 16129 & 7660 & 5565 & 42.33 & 62.60 & 16.67 & 15.62 & -2.12 & -1.49 & 1.04 & -0.81 & 1.22 & 0.67 & 2.52 \\
\hline PTPN21 & 6215 & 551 & 1684 & 565 & 2532 & 1.93 & 5.45 & 1.03 & 5.93 & -1.28 & 1.08 & 3.51 & 0.84 & 3.47 & -0.24 & 2.43 \\
\hline RAB3B & 12844 & 2274 & 10492 & 8012 & 3620 & 3.86 & 16.44 & 7.04 & 4.10 & -1.33 & -1.39 & 1.25 & -1.14 & 1.22 & 0.25 & 2.64 \\
\hline RHOU & 4758 & 16379 & 28644 & 5876 & 7735 & 75.11 & 121.17 & 13.94 & 23.66 & -2.77 & 0.28 & 3.58 & 0.34 & 3.71 & 0.06 & 3.30 \\
\hline SCAP & 4255 & 609 & 869 & 1134 & 4593 & 3.12 & 4.11 & 3.01 & 15.71 & 0.34 & -0.29 & 0.76 & -0.11 & 0.99 & 0.18 & 1.05 \\
\hline SGK1 & 3965 & 105 & 24777 & 20302 & 1347 & 0.58 & 125.78 & 57.79 & 4.94 & 0.24 & -0.10 & 3.35 & -0.05 & 3.62 & 0.05 & 3.45 \\
\hline$S L C 45 A 3$ & 3382 & 5108 & 7039 & 2578 & 15489 & 32.95 & 41.89 & 8.60 & 66.66 & -1.03 & -2.52 & 1.07 & -2.29 & 1.42 & 0.23 & 3.59 \\
\hline TMPRSS2 & 3320 & 4457 & 54020 & 27831 & 19920 & 29.29 & 327.51 & 94.61 & 87.33 & -0.53 & -4.59 & -0.38 & -3.92 & 0.09 & 0.67 & 4.21 \\
\hline WIPI1 & 1924 & 209 & 435 & 6828 & 1472 & 2.37 & 4.55 & 40.05 & 11.14 & 2.15 & -0.10 & 2.57 & 0.98 & 2.86 & 1.08 & 2.67 \\
\hline WWC1 & 6739 & 2465 & 1922 & 6536 & 5735 & 7.98 & 5.74 & 10.95 & 12.39 & 0.26 & -0.75 & 0.16 & -0.99 & 0.21 & -0.23 & 0.91 \\
\hline ZNF350 & 2341 & 2985 & 3161 & 5862 & 1155 & 27.82 & 27.18 & 28.26 & 7.18 & -1.54 & 0.27 & 1.27 & 0.18 & 1.35 & -0.09 & 1.00 \\
\hline
\end{tabular}


Table S6. $R^{2}$ values for regression models that include only AR-FL levels (continuous variable) compared to regression models that additionally include AR-V7 status, for each clinical outcome (PSA response rate, PSA-PFS and PFS).

Footnote: The $\mathrm{R}^{2}$ values are based on the Sums-of-squares method of Mittleböck and Schemper (Computing measures of explained variation for logistic regression models. Computer Methods and Programs in Biomedicine 1999; 58:17-24) for PSA response rate, and on the method of Heller (A measure of explained risk in the proportional hazards model. Biostatistics 2012; 13:315-325) for PSA-PFS and PFS. P-values are based on the Likelihood ratio test.

\begin{tabular}{|l|c|c|c|c|c|c|}
\hline \multirow{2}{*}{ Outcome } & \multicolumn{3}{|c|}{$\begin{array}{c}\text { Regression Models - } \\
\text { Enzalutamide Cohort }\end{array}$} & \multicolumn{3}{c|}{$\begin{array}{c}\text { Regression Models - } \\
\text { Abiraterone Cohort }\end{array}$} \\
\cline { 2 - 7 } & AR-FL alone & AR-FL + AR-V7 & $P$ value & AR-FL alone & AR-FL + AR-V7 & $P$ value \\
\hline PSA Response & $R^{2}=0.307$ & $R^{2}=0.449$ & 0.019 & $R^{2}=0.203$ & $R^{2}=0.336$ & 0.021 \\
\hline PFA-PFS & $R^{2}=0.196$ & $R^{2}=0.573$ & $<0.001$ & $R^{2}=0.651$ & $R^{2}=0.793$ & 0.012 \\
\hline PFS & $R^{2}=0.341$ & $R^{2}=0.649$ & $<0.001$ & $R^{2}=0.869$ & $R^{2}=0.903$ & 0.083 \\
\hline
\end{tabular}




\section{Supplementary References}

1. Hu R, Dunn TA, Wei S, et al. Ligand-independent androgen receptor variants derived from splicing of cryptic exons signify hormonerefractory prostate cancer. Cancer Res 2009;69:16-22.

2. Watson PA, Chen YF, Balbas MD, et al. Constitutively active androgen receptor splice variants expressed in castration-resistant prostate cancer require full-length androgen receptor. Proceedings of the National Academy of Sciences 2010.

3. Hu R, Isaacs WB, Luo J. A snapshot of the expression signature of androgen receptor splicing variants and their distinctive transcriptional activities. The Prostate 2011;71:1656-67.

4. $\mathrm{Hu} \mathrm{R}, \mathrm{Lu} \mathrm{C}$, Mostaghel EA, et al. Distinct transcriptional programs mediated by the ligand-dependent full-length androgen receptor and its splice variants in castration-resistant prostate cancer. Cancer Res 2012;72:3457-62.

5. Luo J, Duggan DJ, Chen Y, et al. Human prostate cancer and benign prostatic hyperplasia: molecular dissection by gene expression profiling. Cancer Res 2001;61:4683-8.

6. Aryee MJ, Liu W, Engelmann JC, et al. DNA methylation alterations exhibit intraindividual stability and interindividual heterogeneity in prostate cancer metastases. Science translational medicine 2013;5:169ra10.

7. Liu W, Laitinen S, Khan S, et al. Copy number analysis indicates monoclonal origin of lethal metastatic prostate cancer. Nature medicine 2009; 15:559-65.

8. Robinson JT, Thorvaldsdottir H, Winckler W, et al. Integrative genomics viewer. Nature biotechnology 2011;29:24-6.

9. Anders S, Pyl PT, Huber W. HTSeq-A Python framework to work with high-throughput sequencing data. bioRxiv 2014.

10. Subramanian A, Tamayo P, Mootha VK, et al. Gene set enrichment analysis: a knowledge-based approach for interpreting genome-wide expression profiles. Proceedings of the National Academy of Sciences of the United States of America 2005;102:15545-50.

11. Norris JD, Chang CY, Wittmann BM, et al. The homeodomain protein HOXB13 regulates the cellular response to androgens. Molecular cell 2009;36:405-16. 